\title{
AVALIAÇÃO DO DESEMPENHO DE EMPRESAS TERCEIRIZADAS COM O USO DA METODOLOGIA MULTICRITÉRIO DE APOIO À DECISÃO - CONSTRUTIVISTA
}

\author{
Leonardo Ensslin* \\ Edilson Giffhorn \\ Sandra Rolim Ensslin \\ Sérgio Murilo Petri \\ William Barbosa Vianna
}

Programa de Pós-graduação em Engenharia de Produção Universidade Federal de Santa Catarina (UFSC)

Florianópolis - SC

ensslin@deps.ufsc.br; edilson.giffhorn@gmail.com

smpetri@gmail.com; wpwilliam@hotmail.com

* Corresponding author / autor para quem as correspondências devem ser encaminhadas

Recebido em 03/2008; aceito em 06/2009 após 1 revisão

Received March 2008; accepted June 2009 after one revision

\section{Resumo}

O objetivo do presente trabalho consiste em construir um modelo para avaliar o desempenho de empresas terceirizadas na área de telecomunicações. Trata-se de um estudo de caso, caracterizando-se como exploratório de natureza prática. Segue uma abordagem quali-quantitativa, tendo como instrumentos para a coleta de dados entrevistas semi-estruturadas com o Gestor de Projetos responsável pela seleção das empresas terceirizadas complementado por análise documental. $\mathrm{O}$ instrumento de intervenção utilizado foi a metodologia MCDA-C. A metodologia permitiu identificar, organizar, mensurar e integrar os critérios. O modelo construído permite ao gerente visualizar o perfil das empresas terceirizadas nos critérios por ele identificados como relevantes para o sucesso de sua organização. O trabalho ilustra para uma das terceirizadas: o perfil de impacto; o resultado numérico de sua avaliação; o processo disponibilizado pelo modelo para gerar alternativas para aperfeiçoar o desempenho da terceirizada e permitir ao gerente compreender as consequências destas ações.

Palavras-chave: avaliação de desempenho; MCDA-C; terceirização.

\begin{abstract}
This paper aims to build an assessment model for the outsourcing companies' performance in the telecommunications sector. It is carried out as a case study, exploratory and it has a practical nature. Using a qualitative-quantitative approach and as instruments for the data collecting we used semistructured interviews with the Project Manager responsible for the selection of the outsourced companies complemented by documental analysis. The intervention instrument used was the MCDA-C. This methodology allows us to: identify, organize, measure and integrate the criteria. The built model enables the company's manager to view the outsourced companies' profile in the criteria identified as important to the success of his organization. The work illustrates for one of the outsourced companies: the impact profile; numeric result for its assessment; the available process using the modeling to generate alternatives to improve the outsourced company's performance, and enabling the manager to understand the consequences of these actions.
\end{abstract}

Keywords: performance assessment; MCDA-C; outsourcing. 


\section{Introdução}

O atual estágio e o ritmo de crescimento econômico do Brasil vêm exigindo um aprimoramento cada vez maior da infraestrutura do país. Um dos setores mais diretamente afetados por este desafio de crescimento é o das telecomunicações, já que, para a configuração de uma sociedade baseada no conhecimento, se utiliza cada vez mais de tecnologias de informação e comunicação como um dos principais traços característicos do desenvolvimento, seja em nível local ou global.

A rapidez das mudanças e as exigências no mercado consumidor de telecomunicações foram marcadas inicialmente pela quebra do monopólio estatal em 1998. A partir desse momento, os novos desafios que se impuseram às empresas operadoras do sistema, tais como o crescente aumento na demanda por serviços de voz e dados, resultaram na necessidade da terceirização de parte dos serviços, o que permitiu a concentração de forças nas competências essenciais.

A inexistência de modelos científicos que explicitem os critérios utilizados para homologar as empresas terceirizadas, com base em processos sistêmicos de avaliação de desempenho, expõe as operadoras à ocorrência de muitos problemas geradores de prejuízos à qualidade, retrabalhos, custos adicionais e, sobretudo, prejuízo para a imagem perante os clientes. Esta situação se evidencia principalmente quando o decisor não tem claro os quesitos a serem tidos em conta no processo de aceitação das empresas terceirizadas para trabalhar em comunicação de dados e voz. Adicione-se a isso que a pressão por compressão dos cronogramas para atingir as metas leva o decisor a decidir sobre o aceite das empresas contratadas e sua gestão posterior de forma predominantemente intuitiva. Estão presentes nessa situação múltiplos critérios não claramente conhecidos.

Nesse contexto, emerge a pergunta da pesquisa: quais os critérios a serem considerados no processo de homologação de empresas terceirizadas, em um modelo que se propõe a apoiar o gerenciamento desses recursos de tal forma a promover a competitividade organizacional?

Com vistas a responder à pergunta de pesquisa proposta pelos autores, o objetivo do presente trabalho - de caráter exploratório - consiste em construir um modelo para avaliar o desempenho de empresas terceirizadas, de tal maneira a permitir o aprimoramento do processo de seleção e gestão dos serviços terceirizados em uma empresa de telecomunicações.

Tendo em vista a ausência de modelos multicritérios para avaliar o desempenho de empresas terceirizadas, que explicitem o processo de estruturação dos valores e preferências de um decisor particular, os objetivos específicos deste trabalho de pesquisa são:

1. Explicitar os atores do contexto e em particular o decisor em nome de quem os valores e preferências serão determinados;

2. Identificar os critérios que o decisor considera necessários e suficientes para avaliar as empresas terceirizadas;

3. Construir escalas ordinais e cardinais para mensurar tais critérios, segundo a percepção do decisor;

4. Integrar os critérios via taxas de compensação, conforme a percepção do decisor;

5. Ilustrar o entendimento gerado pela evidenciação do perfil de impacto das terceirizadas;

6. Evidenciar o processo de avaliação das terceirizadas;

7. Evidenciar o processo de geração de ações de aperfeiçoamento para uma terceirizada, visando mostrar as consequências das mesmas nos critérios. 
O presente artigo descreve um estudo de caso no qual foi desenvolvido um modelo personalizado para um Gestor de Projetos de uma grande empresa de telecomunicações com atuação no Sul do Brasil, em que somente no primeiro semestre de 2007 foram efetuadas mais de 823 obras. Com a construção de um modelo de avaliação de desempenho baseado nos critérios julgados importantes pelo decisor, ele passou a dispor de um instrumento de apoio à decisão ao homologar as empresas. No desenvolvimento de tal modelo, utilizou-se a Metodologia Multicritério de Apoio à Decisão - Construtivista (MCDA-C), por seu diferencial em relação às metodologias MCDA tradicionais para estruturar contextos.

A fonte de coleta dos dados é de natureza primária e secundária, pelo fato de os dados terem sido coletados diretamente junto ao gerente de projetos, via entrevistas não estruturadas, $\mathrm{e}$ junto a documentos internos da organização. A abordagem metodológica utilizada pode ser classificada como quali-quantitativa. Qualitativa na estruturação quando identifica os critérios, constrói as escalas ordinais e quando das Recomendações. Quantitativa quando transforma as escalas ordinais em cardinais e as integra. A lógica da pesquisa é mista, indutiva na etapa da Estruturação e dedutiva na Avaliação.

A relevância da pesquisa pode ser argumentada em termos das contribuições (i) teóricas; e (ii) gerenciais que ela pretende oferecer. Com relação a (i), a proposta teórico-metodológica tem por objetivo oferecer, para uma empresa específica, um procedimento sistematizado para o desenvolvimento das etapas de identificação, mensuração/avaliação e recomendações de aperfeiçoamento dos aspectos da organização julgados pelo decisor como necessários e suficientes para se ter em conta no processo de homologação de empresas terceirizadas. Com relação a (ii), busca-se oferecer um instrumento que permita ao decisor desenvolver seu entendimento do contexto de forma a permitir-lhe explicitar seus valores (critérios) e preferências (funções de valor e taxas de compensação) e as consequências de suas decisões nos mesmos.

O presente artigo é organizado conforme explicado a seguir: seção 1, de caráter introdutório; seção 2, com o constructo teórico da Terceirização e Avaliação de Desempenho; seção 3, com a construção do modelo de avaliação de desempenho do Estudo de Caso, e seção 4, com as Considerações Finais.

\section{Constructo Teórico}

Esta seção se subdivide em duas partes. A primeira apresenta o conceito de Terceirização adotado neste estudo e a nova visão requerida em seu processo de avaliação. A segunda parte contempla as origens e as diferenças entre a MCDA-C, instrumento de intervenção adotado neste trabalho, e a MCDA.

\subsection{Terceirização e Avaliação de Desempenho}

Para ganhar velocidade, flexibilidade e especialização em meio à crescente dinamicidade do ambiente competitivo, as organizações estão promovendo terceirizações de suas atividades suporte, o que permitiu a concentração de forças nas competências essenciais. No entanto, ao assim proceder, as organizações passaram a ter uma estreita relação de dependência com o desempenho das empresas terceirizadas, pois essas vêm a exercer um papel fundamental nos resultados da contratante quanto à qualidade e imagem perante os clientes.

A Terceirização está associada à Especialização Flexível, que significa empresas especializadas atuarem com flexibilidade e velocidade suficientes para atender às constantes

Pesquisa Operacional, v.30, n.1, p.125-152, Janeiro a Abril de 2010 
alterações nas demandas dos clientes. Sua principal característica reside em ser um processo que ocorre quando determinada atividade deixa de ser realizada pelos colaboradores de uma empresa e é transferida a outra, chamada Terceira. Ao assim proceder, a empresa contratante pode focar esforços em sua atividade fim (Ramos, 2002).

A transferência de atividades para terceiros já é praticada pelas organizações há muito tempo. Desde o século XVIII na Inglaterra, atividades muito especializadas ou que não interessavam economicamente eram transferidas a pessoas ou empresas mais capacitadas, externas à organização (Bergamaschi, 2004).

O conceito moderno de terceirização como transferência do sistema produtivo e da flexibilização nas relações trabalhistas teve início com a Segunda Guerra Mundial, devido à necessidade de rápido incremento na produção de armamentos. $\mathrm{O}$ conceito da terceirização evoluiu e deslocou o foco da redução de custos e qualidade para a melhoria do desempenho ao incorporar novas dimensões como: inovação, velocidade e flexibilidade (Hays \& Pisano, 1994). Emerge, a partir de então, a noção de que avaliar o desempenho de uma terceirizada envolvia mais que simplesmente qualidade e valores monetários.

No Brasil, a adoção da Terceirização foi inicialmente gradual, mas ganhou força a partir do início da década de $1990 \mathrm{com}$ o fim das leis de reserva de mercado, do aumento dos custos fixos, da carga tributária e do número de insumos necessários para executar as atividades suporte. No ramo de telecomunicações, a Terceirização foi definitivamente incorporada a uma série de atividades com a privatização das empresas pertencentes ao grupo Telebrás no final da década de 1990. O ambiente torna-se, então, de alta competitividade e as empresas terceirizadas passaram a corresponder a um dos principais diferenciais competitivos.

Emerge assim a questão: "Como selecionar as empresas terceirizadas para melhorar a competitividade do todo?". Para responder a esta pergunta, necessita-se de um instrumento que permita avaliar o desempenho das terceirizadas segundo a percepção de seu gestor (decisor). Autores como Skinner (1986), Roy (1993, 1996, 2005), Keeney (1992), Landry (1995), Bana e Costa et al. (1999), Zimmermann (2000), Shenhar (2001), Steward (2005), Igarashi et al. (2008), dentre outros, alertam para a necessidade de se considerar os valores individuais do(s) decisor(es) ao construir os modelos para avaliar o desempenho de sistemas organizacionais, em detrimento das metodologias que se valem de valores e preferências coletivas ou determinadas via métodos estatísticos, ou mesmo utilizadas com sucesso no passado. Em face dessa delimitação, para a estruturação do modelo de avaliação de desempenho, propõe-se como instrumento de intervenção a Metodologia Multicritério de Apoio à Decisão Construtivista (MCDA-C).

\subsection{A MCDA-C e as metodologias MCDA tradicionais}

A MCDA-C encontra suas mais remotas origens há mais de dois séculos. Contudo, sua consolidação como instrumento científico de gestão ocorre somente a partir da década de 1980 com os trabalhos de Roy (1996) e Landry (1995) ao definir os limites da objetividade para os processos de apoio à decisão, de Skinner (1986) e Keeney (1992) ao reconhecer que os atributos (objetivos, critérios) são específicos ao decisor em cada contexto, de Bana e Costa (1993) ao explicitar as convicções da MCDA, dentre outros.

A MCDA-C surge como uma ramificação da MCDA tradicional para apoiar os decisores em contextos complexos, conflituosos e incertos. Complexos por envolverem múltiplas variáveis qualitativas e quantitativas, parcialmente ou não explicitadas. Conflituosos por envolverem 
múltiplos atores com interesses não necessariamente alinhados e/ou com preocupações distintas do decisor que não tem interesse de confrontá-los, mesmo reconhecendo que estes estarão disputando os escassos recursos. Incertos por requererem o conhecimento de informações qualitativas e quantitativas que os decisores reconhecem não saber quais são, mas que desejam desenvolver este conhecimento para poder tomar decisões conscientes, fundamentadas e segundo seus valores e preferências (Zimmermann, 2000). O procedimento de um grupo representativo de pesquisadores particularizar suas técnicas em MCDA para melhor identificar suas linhas de trabalho não é novo, como pode ser constatado no European Working Group “Multicriteria Aid for Decisions”, series 3, $n^{\circ}$ 7, Spring 2003, que apresenta o reconhecimento da necessidade de se ter em conta as percepções dos decisores e estruturar os contextos, quando da utilização da MCDA, e propõe a incorporação da sigla SMCDA:

[...] agree with them on the need of extending MCDA by incorporating the notion of stakeholder; this is the reason why a social multi-criteria process must be as participative and as transparent as possible; although I argue that participation is a necessary condition but not a sufficient one. This is the main reason I propose the concept of "Social Multi-criteria Evaluation" (SMCE) in substitution of "Participative Multi-criteria Evaluation" (PMCE) or "Stakeholder Multi-criteria Decision Aid" (SMCDA). (Munda, 2003, p. 2-3)

Em termos teóricos metodológicos, a distinção entre a MCDA-C e as metodologias MCDA tradicionais reside notadamente no fato da MCDA tradicional restringir o apoio à decisão a uma etapa de formulação e outra de avaliação para selecionar, segundo um conjunto definido de objetivos (com pouca ou nenhuma participação do decisor), qual, dentre as alternativas previamente estabelecidas, é a melhor (ótima) (Keeney, 1992), (Roy \& Bouyssou, 1993), (Roy, 1996), (Goodwin \& Wright, 1998). A lógica de pesquisa da MCDA tradicional é a racionalista dedutiva, enquanto que a MCDA-C utiliza uma lógica de pesquisa construtivista mista (indutiva e dedutiva) (Roy, 1993). A problemática das metodologias MCDA tradicionais é a da escolha da solução ótima dentre alternativas preexistentes, cujos exemplos dessa visão podem ser encontrados em Zambon et al. (2005), Gomes (2005), Campos \& Almeida (2006), Chen, Kilgour \& Hipel (2008), dentre outros.

Keeney (1992) denomina as abordagens tradicionais da MCDA de Alternative Focus Thinking. Roy (1994) assim se refere a esta visão racionalista da MCDA:

This is a reductionist conception of OR which I would call unproductive. It is largely responsible for what has been called the OR crisis. First of all, this conception of OR tends to cut it off from the milieu which nourishes it and legitimates it as something other than a branch of mathematics. Cutting off $O R$ in this way encourages researchers to work in isolation. This results in naive or impoverished references to managerial reality and decision-making processes. Those responsible for solving concrete problems are thus inevitably disappointed by the gap between their own expectations and the results they receive.

Heijden (1996, p. 232-235) rejeita a visão da MCDA restrita à escolha racionalista da resposta certa. Steward (2005, p. 461) assim se posiciona sobre o uso da lógica racionalista da pesquisa em MCDA: "[...] are rather limited and technocratic view of decision analysis, contrary to the constructive and learning view espoused by most in the MCDA field". O mesmo autor, (Ibid., p. 446 e 447) afirma que inúmeros outros autores se alinham com ele 
para afirmar que um importante aspecto da MCDA que ainda permanece com desenvolvimento e aplicação limitada é a etapa de estruturação, por alguns denominada incerteza interna. Steward (Ibid., p. 446) menciona a citação de Zimmermann (2000, p. 192): "Uncertainty implies that in a certain situation a person does not possess the information which quantitatively and qualitatively is appropriate to describe, prescribe or predict deterministically and numerically a system, its behavior or other characteristics".

Segundo Roy (1994, 1996, 2005), os pesquisadores em MCDA podem ser classificados em dois grupos: aqueles que assumem um posicionamento racionalista e aqueles que adotam o construtivismo como lógica de investigação. Adicione-se ainda que, mesmo entre os adeptos da visão construtivista, muitos têm dificuldades para operacionalizar a etapa de estruturação em uma forma que reconheça os limites da objetividade. Este contexto estimulou alguns autores, que em seus instrumentos de pesquisa contemplam e priorizam esta etapa, a designála por MCDA-C para enfatizar a diferença da lógica de pesquisa. O uso dessa designação pode ser verificado em Correa (1996); Bana e Costa et al. (1999); Ensslin, Dutra \& Ensslin (2000); Ensslin, Longaray \& Mackness (2005); Sannemann et al. (2006); Longaray et al. (2006); Igarashi et al. (2008), dentre outros.

A metodologia MCDA-C reconhece os limites da objetividade como proposto por Roy (1996, 2005), Bana e Costa (1993), Keeney (1992), Landry (1995), Zimmermann (2000), Ensslin, Dutra \& Ensslin (2000), Shenhar (2001) e, por meio do uso de instrumentos tais como entrevistas abertas, brainstorming não estruturados, grafos, mapas de relações meiofim, modelos de otimização, etc., os operacionaliza. E, assim, desenvolve no decisor um coerente corpo de conhecimentos capaz de lhe permitir compreensão das consequências de suas decisões nos aspectos que ele (decisor) julga importantes, sem impor os racionalismos da objetividade, tão úteis na física e na matemática, porém dissociados dos contextos decisórios específicos em que os decisores:

- Necessitam de apoio para explicitar e mensurar seu(s) valor(es) e preferências;

- Desejam ter em conta seu(s) valor(es) e preferências, e não valor(es) e preferências genéricos ou de outros casos similares, mesmo os bem sucedidos;

- Desejam poder compreender e visualizar as consequências de suas decisões em seus objetivos (critérios);

- Desejam estabelecer as performances de referências em cada objetivo (critério) segundo sua percepção;

- Desejam compreender a contribuição de cada objetivo (critério) nos objetivos estratégicos;

- Desejam valer-se da expansão do conhecimento propiciado pelo processo de apoio à decisão para identificar oportunidades de aperfeiçoamento.

Este conjunto de demandas faz com que a metodologia MCDA-C tenha como sua principal vocação o processo de desenvolver o conhecimento do decisor sobre o contexto. O processo de desenvolvimento do conhecimento do decisor é realizado na metodologia MCDA-C em forma sistêmica e sistemática em três grupos de atividades: Estruturação, Avaliação e Recomendações, conforme ilustrado na Figura 1. A etapa da Estruturação contribui ao identificar, organizar e mensurar ordinalmente as preocupações que o decisor considera necessárias e suficientes para a avaliação do contexto. A Avaliação é utilizada como um instrumento para melhorar o entendimento ao construir escalas cardinais e taxas de substituição para representar suas preferências locais e globais. E, finalmente, a etapa de Recomendações, que continua o processo de expansão de seu entendimento do contexto ao 
buscar compreender as consequências de suas possíveis decisões nos critérios representativos das dimensões por ele consideradas relevantes, assim como no contexto como um todo.

A visão de fornecer apoio à decisão por meio do desenvolvimento do conhecimento do contexto existe mesmo antes da MCDA existir como área de conhecimento estabelecido. Um exemplo disto é a carta de Benjamin Franklin a Joseph Priestly, datada de 19 de setembro de 1772 (Bana e Costa; Steward \& Vansnick, 1995, p. 2). A partir de então, pesquisadores sistematicamente têm alertado para essa necessidade, como pode ser atestado em Keeney \& Raiffa (1976), Landry (1985), Roy (1993, 1996, 2005), Bana e Costa (1990, 1993, 2005), Keeney (1992), Dvir et al. (1998), Ensslin, Dutra \& Ensslin (2000), Shenhar (2001), Bana e Costa et al. (2008).

Para Keeney (1992, p. 3), "Values are what we care about. [...] They should be the basis for the time and effort we spend thinking about decisions. [...] Instead, decision making usually focuses on the choice among alternatives."

Tendo em vista as diferenças teóricas e práticas dos métodos MCDA tradicionais em suas mais diversas denominações (MCDA, AHP, MAUT, MAVT, SMART, etc.), a metodologia proposta foi denominada MCDA-C.

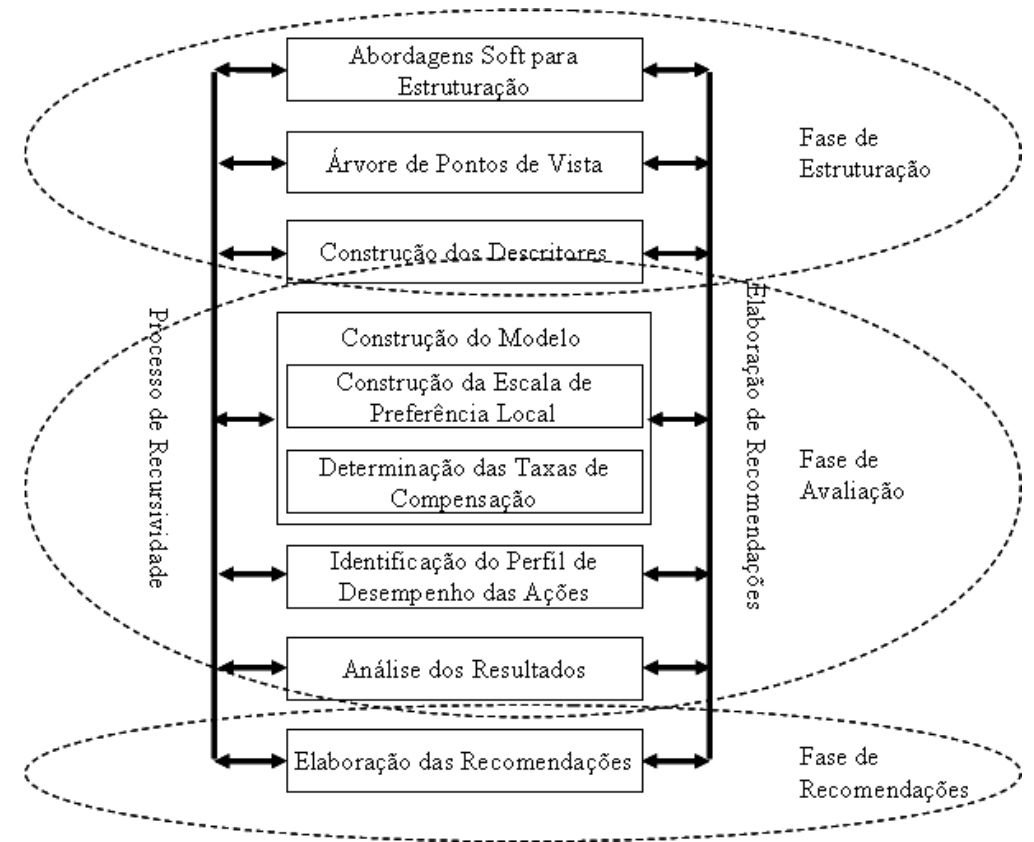

Figura 1 - Fases da MCDA-C.

Fonte: Ensslin, Dutra \& Ensslin (2000)

\section{Construção do Modelo para Avaliação do Desempenho das Terceirizadas}

Em situações complexas, conflituosas e incertas como a do presente estudo, em que estão presentes a disputa de poder e a influência de diferentes atores, e que envolvem múltiplos e conflitantes critérios parcialmente conhecidos, metodologias do tipo multicritério que 
reconhecem os limites da objetividade emergem como o instrumento de intervenção recomendado (Roy, 1993; Roy \& Vanderpooten, 1996). A seleção da metodologia MCDA-C para auxiliar no processo de construção do modelo para homologação e gerenciamento das terceirizadas deve-se ao fato de ela partir da hipótese de que o gerenciamento é um processo contínuo materializado por meio de decisões para a implementação de ações de melhoria e ser um processo social que envolve indivíduos, valores, percepções, assim como relações de poder entre eles.

\subsection{Estruturação do Modelo}

Nessa fase, o contexto do problema é estruturado e organizado a partir dos aspectos julgados mais relevantes pelo decisor. É identificado o subsistema dos atores, fornecido um rótulo que represente o que se busca e identificados, organizados e mensurados ordinalmente os objetivos julgados pelos decisores como necessários e suficientes para avaliar o contexto, de acordo com seus valores e preferências.

\subsubsection{Contextualização, Subsistema de Atores e Rótulo}

O Estudo de Caso foi desenvolvido na filial de uma operadora de telecomunicações localizada no Estado de Santa Catarina, na região Sul do Brasil, com área de $95.346,18 \mathrm{~km}^{2} \mathrm{e}$ população estimada em 5.866.568, segundo dados do IBGE (2007).

Até o início da década de 1990, o sistema de telecomunicações brasileiro era um monopólio estatal, em que as empresas estaduais pertenciam à holding Telebrás. A partir do Programa Nacional de Desestatização, a privatização tornou-se parte integrante das reformas do governo federal. Em 1995 se iniciou a privatização no ramo das telecomunicações e em 1998 foram vendidas as 12 empresas criadas com o desmembramento do sistema Telebrás.

Neste contexto, situa-se a empresa do Estudo de Caso. A empresa pesquisada possui mais de 10 milhões de linhas telefônicas, cerca de seis mil colaboradores e sua área de atuação abrange aproximadamente $33 \%$ do território nacional. Na sua matriz são efetuados os contratos com os fornecedores e, também, é onde se situa o planejamento dos projetos de comunicações de dados. Em suas filiais, os projetos aprovados pela matriz são gerenciados por Gestores de Projeto, que interagem com os técnicos das empresas terceirizadas responsáveis pela execução das obras. As empresas terceirizadas, para poderem atuar, devem ser homologadas pelo Gestor de Projetos, que emite seu parecer e o envia à matriz.

Porém, o processo para avaliar as empresas terceirizadas que estavam sob a responsabilidade do Gestor de Projetos não evidenciava os quesitos julgados relevantes e, por consequência, a homologação das empresas era efetuada de forma intuitiva. Tal procedimento mantinha o Gestor de Projetos vulnerável quanto às suas decisões de aceitar ou não as empresas, também como não permitia um feedback às terceirizadas que proporcionasse oportunidades de aperfeiçoamento na performance das mesmas.

Diante disso, fez-se a identificação de para quem seria feito o Apoio à Decisão, quem eram os atores com poder de interferência no processo e aqueles com interesse nas decisões a serem tomadas. O Quadro 1 representa o Subsistema de Atores envolvidos. 
Quadro 1 - Subsistema de Atores.

\begin{tabular}{|l|l|l|}
\hline \multirow{4}{*}{ Stakeholders } & Decisor & Gestor de Projetos \\
\cline { 3 - 3 } & \multirow{4}{*}{ Intervenientes } & Anatel \\
\cline { 3 - 3 } & & Diretoria de Rede \\
\cline { 3 - 3 } & & Fiscais de campo \\
\cline { 3 - 3 } & & Fornecedores \\
\cline { 3 - 3 } Agidos & Facilitadores & Gerência de Controle de Falhas \\
\hline \multirow{4}{*}{} & & Clientes da empresa \\
\hline & & Sociedade \\
\cline { 3 - 3 } & & Técnicos terceirizados \\
\hline
\end{tabular}

Posteriormente, por meio de um processo interativo entre os facilitadores e o decisor, foi elaborado um Rótulo o mais representativo possível quanto às principais preocupações do decisor em relação ao problema. O Rótulo do Estudo de Caso foi definido como: Construir um modelo para avaliar o desempenho de empresas terceirizadas.

\subsubsection{Elementos Primários de Avaliação, Conceitos e Áreas de Preocupação}

Para o levantamento dos dados relativos ao sistema de valores, foram gravadas entrevistas abertas com o decisor. Nas entrevistas, foi solicitado que o decisor discorresse a respeito do problema. Suas declarações foram analisadas para identificar os Elementos Primários de Avaliação (EPAs), que são as características ou propriedades do contexto que o decisor julga que impactam em seus valores. O maior número possível de EPAs deve ser identificado e novos podem surgir com a combinação dos preexistentes. A análise das entrevistas permitiu a identificação inicial de 60 EPAs. Os 10 primeiros estão ilustrados no Quadro 2.

Quadro 2 - Os dez primeiros EPAs identificados

\begin{tabular}{|c|l|}
\hline EPA & \multicolumn{1}{|c|}{ Descrição } \\
\hline 1 & Capacidade técnica \\
\hline 2 & Agilidade dos técnicos \\
\hline 3 & Estética das instalações \\
\hline 4 & Lançamento dos cabos \\
\hline 5 & Amarração dos cabos \\
\hline 6 & Número de testes realizados \\
\hline 7 & Identificação (etiquetagem) das instalações \\
\hline 8 & Aviso de pendências \\
\hline 9 & Gerente de Projetos na terceirizada \\
\hline 10 & Informação de ativação \\
\hline
\end{tabular}


A partir dos EPAs, a metodologia MCDA-C recomenda expandir seu entendimento identificando a direção de preferência representada por cada um, assim como seu oposto psicológico para entender o grau mínimo de aceitabilidade do objetivo subjacente. Essa forma evolutiva de apresentar o EPA denomina-se conceito ou conceito orientado para a ação (Éden \& Ackermann, 1992). Sua obtenção é feita ao definir o objetivo subjacente ao EPA e, a seguir, ser solicitado ao decisor que fale a respeito do EPA, identificando: desempenho melhor possível; desempenho bom; desempenho ruim; desempenho pior possível (ainda aceitável) e a performance atual, bem como a intensidade que julga ser passar do intervalo pior possível ao intervalo melhor possível. Essa intensidade se reflete no verbo a ser utilizado na construção do conceito. O Quadro 3 exibe os Conceitos para os 10 primeiros EPAs, onde a reticência (...) deve ser lida como "é preferível a" ou "ao invés de" e corresponde ao oposto psicológico.

Quadro 3 - Os dez primeiros Conceitos.

\begin{tabular}{|c|l|}
\hline Conceito & \multicolumn{1}{|c|}{ Descrição } \\
\hline C 1 & $\begin{array}{l}\text { Melhorar capacitação do quadro técnico... ter retrabalho devido obras fora dos } \\
\text { padrões }\end{array}$ \\
\hline C 2 & $\begin{array}{l}\text { Ter técnicos com agilidade na execução dos serviços... atrasar pagamento por } \\
\text { entrega de obra fora do prazo }\end{array}$ \\
\hline C 3 & $\begin{array}{l}\text { Realizar instalações observando a estética... ter atritos com outras áreas devido } \\
\text { aspecto geral da instalação }\end{array}$ \\
\hline C 4 & $\begin{array}{l}\text { Ter em conta as previsões de futuras ampliações quando da instalação dos cabos... } \\
\text { ter de ampliar calhas e reacomodar cabos }\end{array}$ \\
\hline C 5 & $\begin{array}{l}\text { Assegurar que o cabo utilizado e as atividades de seu lançamento atendam os } \\
\text { padrões... gerar retrabalho devido cabo não adequado }\end{array}$ \\
\hline C 6 & $\begin{array}{l}\text { Garantir testes realizados em todos os pontos de acesso... testar por amostragem e } \\
\text { entregar circuitos com defeito }\end{array}$ \\
\hline C 7 & Fazer identificação das instalações... receber multas da Anatel \\
\hline C 8 & Enviar aviso de pendências... ocasionar deslocamentos desnecessários do auditor \\
\hline C 9 & $\begin{array}{l}\text { Possuir Gerente de Projetos... ter atritos com terceirizada pelo recebimento de } \\
\text { informações incorretas }\end{array}$ \\
\hline C 10 & $\begin{array}{l}\text { Enviar e-mail comunicando ativação... atrasar liberação para a área comercial devido } \\
\text { à não informação da conclusão dos serviços }\end{array}$ \\
\hline
\end{tabular}

Os conceitos que representam preocupações estratégicas equivalentes, segundo a percepção do decisor, podem ser agrupados em Áreas de Preocupação. Isto permite reunir os primeiros conceitos que explicam os valores do decisor e as propriedades do contexto que o mesmo tem em conta ao avaliar esta área (Bana e Costa et al., 1999; Ensslin, Dutra \& Ensslin, 2000). Os nomes dados às áreas devem refletir da melhor forma possível a preocupação principal do decisor ao expressar os conceitos pertencentes ao agrupamento. Destaque-se, no entanto, que quem reflete o que é a área são os conceitos, e não o nome dado à mesma.

A Figura 2 mostra as Áreas de Preocupação do Estudo de Caso e a numeração dos respectivos conceitos que as compõem. 


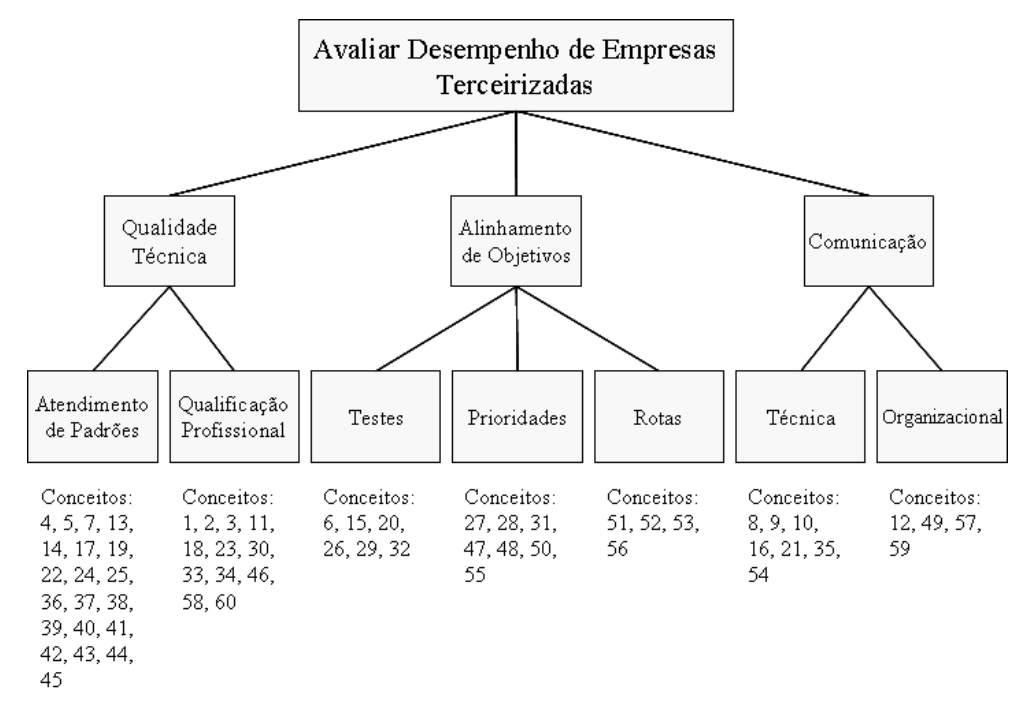

Figura 2 - Agrupamentos dos conceitos em Áreas de Preocupação.

\subsubsection{Mapas Meios-Fins e Árvore de Pontos de Vista Fundamentais}

A partir dos conceitos geradores das áreas, a metodologia MCDA-C expande mais ainda o entendimento por meio da identificação das relações de hierarquia e das relações de influência entre os conceitos. Para tal, vale-se de mapas de relações meios-fins (Bana e Costa et al., 1999; Ensslin, Dutra \& Ensslin, 2000). Sua construção se obtém solicitando ao decisor que discorra para cada conceito: "Como se pode obter o conceito fim?" e "Por que o conceito meio é importante?".

Considere-se, por exemplo, o Conceito 30 - "Possibilitar condições de funcionamento... gerar reclamações dos clientes devido aos equipamentos não estarem configurados com todas as funcionalidades", ilustrado na Figura 3. O facilitador solicitou ao decisor para falar como esse Conceito poderia ser obtido, ou seja, voltou sua atenção em direção aos meios. Sob esse foco, o decisor considerou que o Conceito 30 poderia ser obtido por meio do Conceito 11 "Não interferir na Operação e Manutenção... gerar reclamações dos clientes afetando indicador de Manutenção e Operação", do Conceito 23 - "Não paralisar equipamentos ativos no sistema... gerar defeitos por intervenções indevidas em equipamentos ativos", e do Conceito 46 - "Reduzir perda financeira por receita cessante... receber multa por paralisar sistemas operantes". Em seguida, voltou sua atenção para os fins, ou seja, o facilitador questionou o decisor por que o Conceito 30 era importante. $\mathrm{O}$ decisor considerou que o Conceito 30 era importante porque era um resultado da operacionalização do Conceito "Fornecer treinamento às equipes... técnicos aprenderem somente com a realização dos serviços". Ou seja, o treinamento formal aos técnicos proporcionaria a realização de serviços de forma mais ágil, aumentaria a possibilidade dos equipamentos serem entregues em condições de liberação comercial e de as instalações serem feitas atendendo os padrões estéticos.

Esse processo foi repetido para cada conceito até se estabelecerem todas as relações de causa-efeito entre eles. Durante o processo de construção do mapa, podem surgir novos conceitos não identificados anteriormente, como foi o caso do conceito "Fornecer treinamento às equipes... técnicos aprenderem somente com a realização dos serviços". 
Para facilitar a análise e entendimento, o Mapa Meios-Fins é dividido em mapas menores formando os Clusters. Os Clusters são formados ao serem agrupados os ramos cuja argumentação reflita uma mesma preocupação do decisor e não existam relações de influência entre Clusters. Ao percorrer um ramo, o decisor segue uma linha de argumentação que conduz de um determinado conceito meio até o objetivo expresso pelo rótulo do problema. O nome de cada Cluster é dado em função do foco de interesse do decisor expresso pelos ramos que o compõem.

A Figura 3 ilustra o Mapa Meios-Fins para os Clusters Qualificação Profissional e Testes. Os conceitos não numerados são os que emergiram no momento da construção do Mapa.

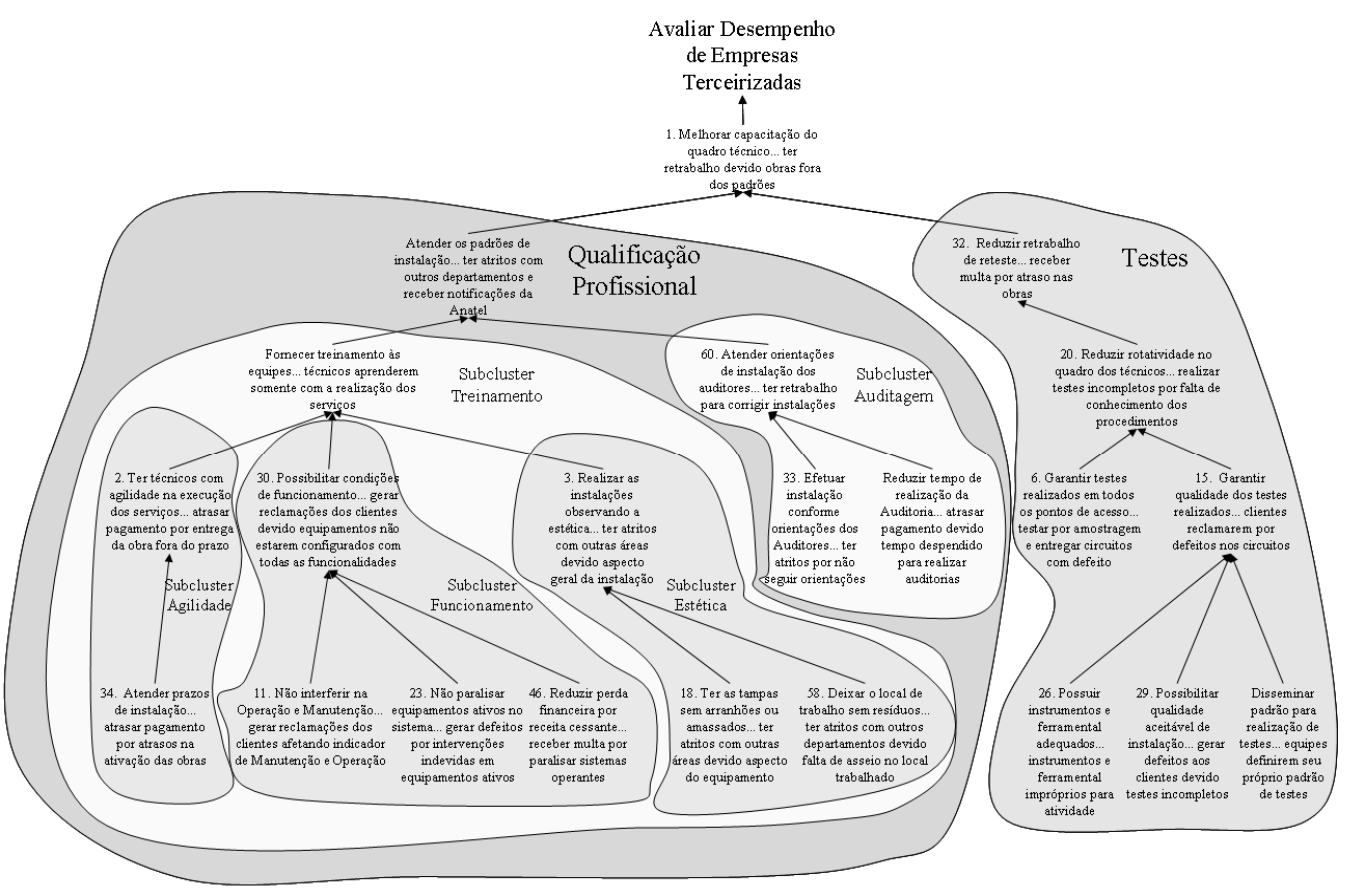

Figura 3 - Mapa Meios-Fins para os Clusters Qualificação Profissional e Testes.

Uma vez construídos todos os mapas, a metodologia MCDA-C propõe, para continuar seu processo de construir o entendimento, que a estrutura de relações de influência seja convertida em uma estrutura hierárquica de valor. Isto permite incorporar o entendimento dos julgamentos preferenciais do decisor no modelo em construção (Keeney, 1992).

Uma preocupação a ser considerada é de que os Clusters iniciais devem ser testados para representarem aspectos do contexto de forma a ser: essencial, controlável, completo, mensurável, operacional, isolável, não-redundante, conciso e compreensível (Keeney, 1992; Ensslin, Montibeller \& Noronha, 2001; Roy, 2005, p. 10). Isto faz com que muitos Clusters iniciais tenham de ser desmembrados até que alcancem as propriedades acima. Uma vez atendidas estas propriedades, cada novo cluster, ao migrar para a estrutura hierárquica de valor, recebe a denominação de Ponto de Vista Fundamental (PVF). 
À representação do Rótulo, Áreas de Preocupação e os respectivos Pontos de Vista Fundamentais dá-se o nome de Estrutura Hierárquica de Valor, conforme destacado na Figura 4 para o modelo construído para o Estudo de Caso.

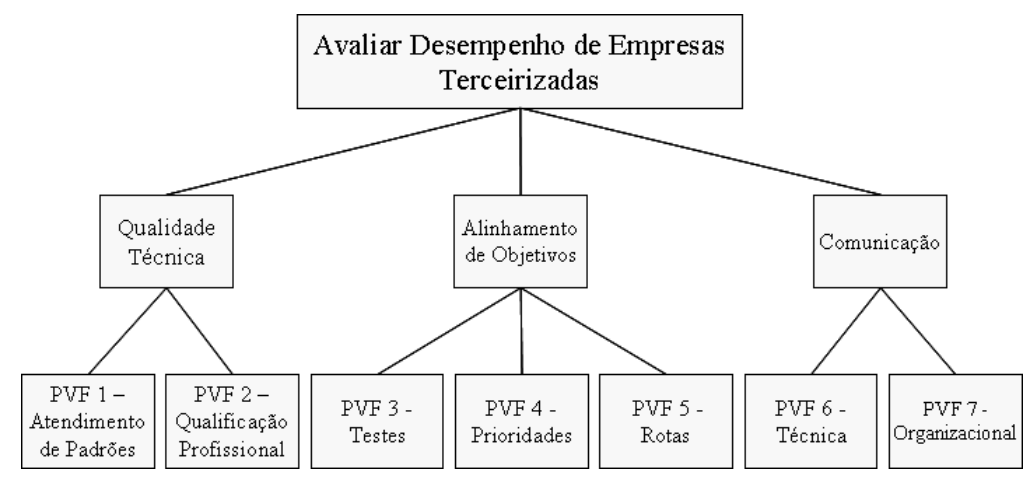

Figura 4 - Estrutura Hierárquica de Valor.

\subsubsection{Estrutura Hierárquica de Valor e Descritores}

No entanto, os PVFs ainda são demasiado abrangentes para serem mensurados. Por isso, retornase aos Mapas Meios-Fins e analisam-se os subclusters. Tais subclusters devem obedecer às mesmas propriedades dos Clusters iniciais e seu processo de transformação é equivalente ao utilizados para os PVFs e estes subcritérios são denominados Pontos de Vista Elementares (PVEs). Este processo de decomposição continua até que se obtenha um PVE que represente uma propriedade do contexto e assim possa ser mensurado em forma objetiva, e não ambígua.

Seja, por exemplo, o $\mathrm{PVF}_{2}$ - Qualificação Profissional. No Mapa Meios-Fins, o Cluster da Qualificação Profissional é composto por dois subclusters, conforme pode ser verificado na Figura 3, um que representa a preocupação em relação a Treinamento-capacitação e outro para a Auditagem. Como eles ainda não podem ser mensurados adequadamente, essas preocupações foram decompostas em três subclusters: Agilidade, Funcionamento e Estética, em que Agilidade e Estética podem ser mensurados diretamente. O subcluster Funcionamento, por sua vez, foi decomposto em outros três subclusters: Indicadores de O\&M, Intervenções Indevidas e Receita Cessante, que, ao migrarem para a estrutura hierárquica, geraram os correspondentes PVEs, permitindo a construção de escalas ordinais de mensuração.

Uma vez construída a Estrutura Hierárquica de Valor, a metodologia MCDA-C propõe como passo seguinte a construção de escalas ordinais para mensurar os Pontos de Vista constituintes. A estas escalas ordinais denomina-se Descritor.

As escalas ordinais são construídas em um processo interativo com o decisor, que uma vez tenha construído a escala que melhor represente aquilo que ele julga relevante, identifica os Níveis de Referência, ou Âncoras, denominados Nível Bom, que representa o nível acima do qual o decisor julga a performance como excelente, e Nível Neutro, abaixo do qual o desempenho é comprometedor. Entre os dois pontos, o desempenho é competitivo (Roy, 2005, p.14).

A Figura 5 ilustra a Estrutura Hierárquica de Valor para o PVF Qualificação Profissional, com os correspondentes PVEs e Descritores. Para o modelo como um todo, foram construídos 54 descritores. 


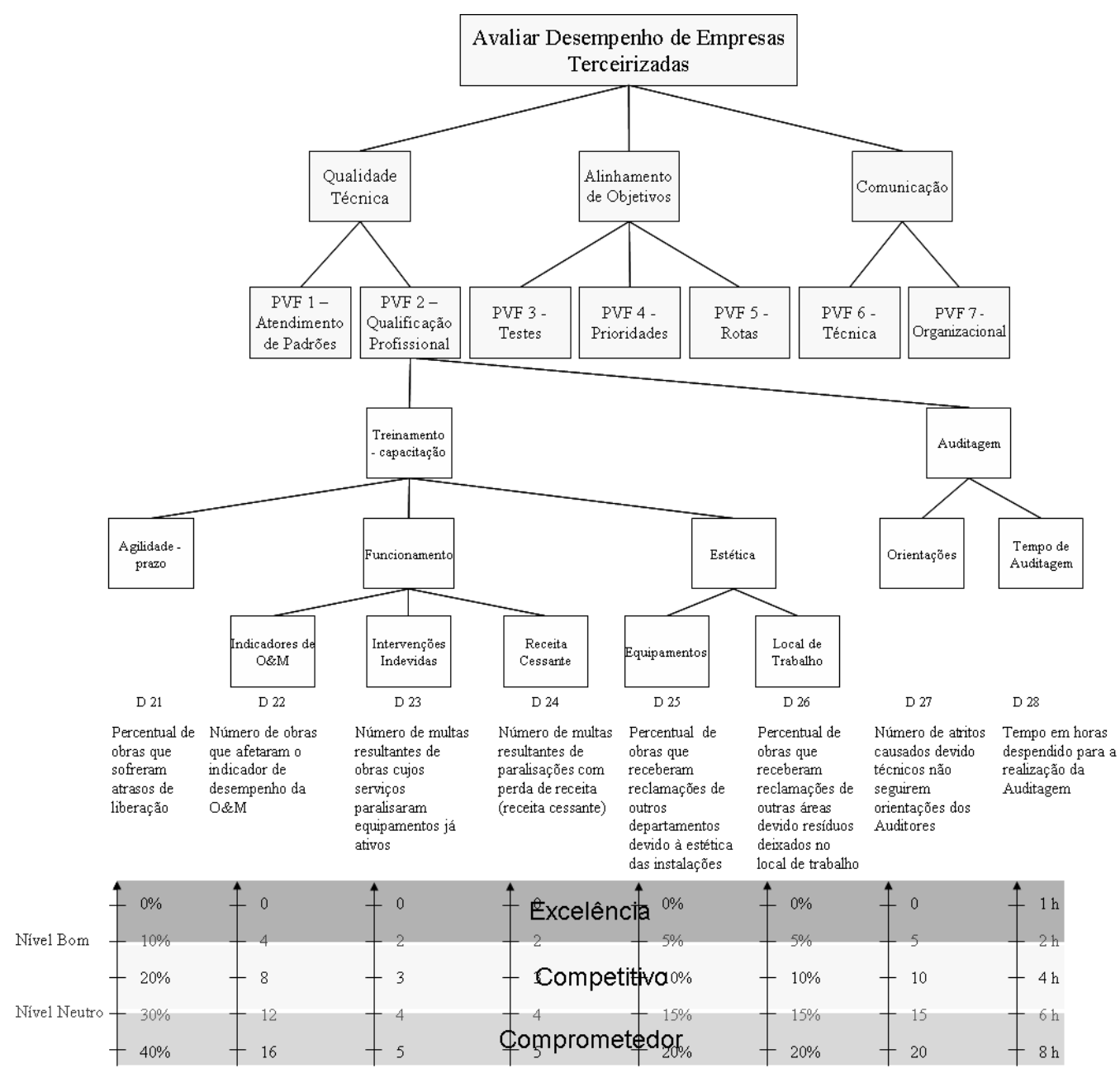

Figura 5 - Estrutura Hierárquica de Valor para o $\mathrm{PVF}_{2}$ - Qualificação Profissional, com os PVEs e Descritores.

Ao concluir a construção da Estrutura Hierárquica de Valor com os Descritores, desenvolveu-se todo o entendimento do contexto permitido por uma estrutura não numérica (escalas nominais e ordinais). Para continuar o processo de entendimento, devem ser incorporadas informações que possibilitem transformar as escalas ordinais em cardinais, que é o propósito da etapa seguinte da metodologia MCDA-C.

\subsection{Avaliação}

Ao concluir a etapa de estruturação, a metodologia MCDA-C terá construído um modelo contendo os aspectos julgados pelo(s) decisor(es) como necessários e suficientes para avaliar o contexto. As escalas neste modelo são ordinais e denominadas Descritores, conforme Figura 5. As referidas escalas muitas vezes se valem de símbolos numéricos para sua 
representação, estes, no entanto, são simplesmente símbolos alfa-numéricos, e não números do conjunto $\mathfrak{R}$ (conjunto dos números reais), para mais detalhes, ver Ensslin, Montibeller \& Noronha (2001), Barzilai (2001) e Azevedo (2001). É equivocado, portanto, utilizar estas escalas para qualquer função que envolva operações numéricas, pois elas não são numéricas. A MCDA-C reconhece as diferenças entre as escalas ordinais e cardinais e, para realizar a transformação, necessita mais uma vez a participação do decisor para fornecer informações que permitam conhecer a diferença de atratividade entre os níveis de cada escala. Esta atividade pode ser realizada por variados métodos, tais como: Pontuação Direta, Bissecção, MACBETH, dentre outras (Ensslin, Montibeller \& Noronha, 2001). A MCDA-C vale-se de todos estes métodos para transformar as escalas ordinais em cardinais. $\mathrm{O}$ método MACBETH, por sua fundamentação teórica, representatividade e reconhecimento prático, tem sido o mais empregado, pelo que será o utilizado neste trabalho.

Destaque-se que o Macbeth - Measuring Attractiveness by a Cathegorical Based Evaluation Technique é unicamente um método para transformar escalas ordinais em cardinais a partir de juízos absolutos sobre a diferença de atratividade entre duas alternativas, e não uma metodologia de apoio à decisão como AHP, MCDA, MAUT, MAVT, SMART, como pode ser evidenciado em Bana e Costa, De Corte \& Vansnick, (2005, p. 437): "The MACBETH approach and the M-MACBETH software have been used to derive preference scales or value functions and scaling constants in many public and private applications of multicriteria additive value analysis, some of them reported in the literature".

\subsubsection{Funções de Valor}

Obtidos os Descritores de todos os pontos de vista, a metodologia MCDA-C, seguindo seu propósito de construir o entendimento do decisor, solicita a ele que informe a diferença de atratividade entre os níveis dos descritores (escalas ordinais). A partir destas informações, com a ajuda do software M-Macbeth, constroem-se escalas cardinais que atendam os juízos de preferências do decisor. Estas escalas denominam-se Funções de Valor.

O procedimento de uso do método MACBETH consiste em solicitar ao decisor que expresse a diferença de atratividade entre duas alternativas potenciais $\boldsymbol{a}$ e $\boldsymbol{b}(\boldsymbol{a}$ mais atrativa que $\boldsymbol{b})$ com base em uma escala ordinal de sete categorias semânticas propostas a priori ao decisor para cada intervalo do descritor (Bana e Costa \& Vansnick, 1995). Os níveis de atratividade da escala semântica são: nula, muito fraca, fraca, moderada, forte, muito forte e extrema. Em seguida, são estabelecidos os Níveis de ancoragem Bom (100) e Neutro (0), transformando a escala em uma Escala de Intervalos Ancorada. Deste modo, os Níveis Âncora Bom e Neutro terão igual grau de atratividade para todos os descritores e igual pontuação numérica para todas as funções de valor.

Com base nas respostas do decisor, constrói-se a Matriz de Julgamentos, cujos valores servem de entrada para o software determinar a função de valor.

A Figura 6 apresenta o processo completo de transformação de um descritor (escala ordinal) em uma Função de Valor (escala cardinal): o descritor D1 - Cláusulas Contratuais; a Matriz de Julgamento; a escala ancorada fornecida pelo software M-Macbeth e a Função de Valor, numérica e gráfica. 


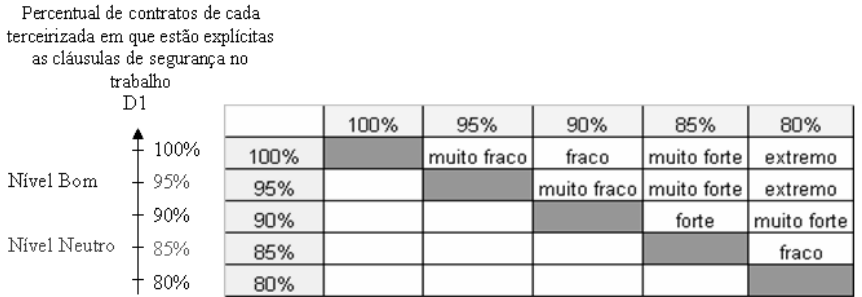

Percentual de contratos de cada erceirizada em que estão explicitas

\begin{tabular}{|c|c|c|c|c|c|c|c|}
\hline \multirow{4}{*}{ Nivel Bom } & \multirow{3}{*}{$\begin{array}{l}\hat{f}_{100 \%} \\
-95 \%\end{array}$} & & $100 \%$ & $95 \%$ & $90 \%$ & $85 \%$ & $80 \%$ \\
\hline & & $100 \%$ & & muito fraco & fraco & muito forte & extremo \\
\hline & & $95 \%$ & & & muito fraco & muito forte & extremo \\
\hline & $-90 \%$ & $90 \%$ & & & & forte & muito forte \\
\hline \multirow[t]{2}{*}{ Nivel Neutro } & $-85 \%$ & $85 \%$ & & & & & fraco \\
\hline & $-80 \%$ & $80 \%$ & & & & & \\
\hline
\end{tabular}
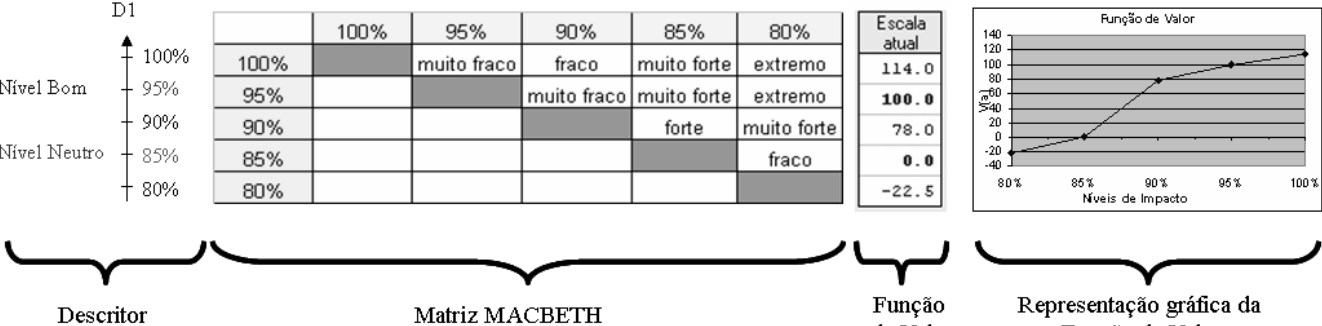

Escala Ordina
Matriz MACBETH

Transformação Semântica

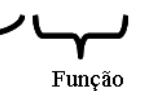

Representação gráfica da

Função de Valor

Figura 6 - Transformação do Descritor Cláusulas Contratuais em Função de Valor por meio do Método MACBETH.

A Figura 7 apresenta o conjunto de escalas cardinais construídas para o PVF Qualificação Profissional.

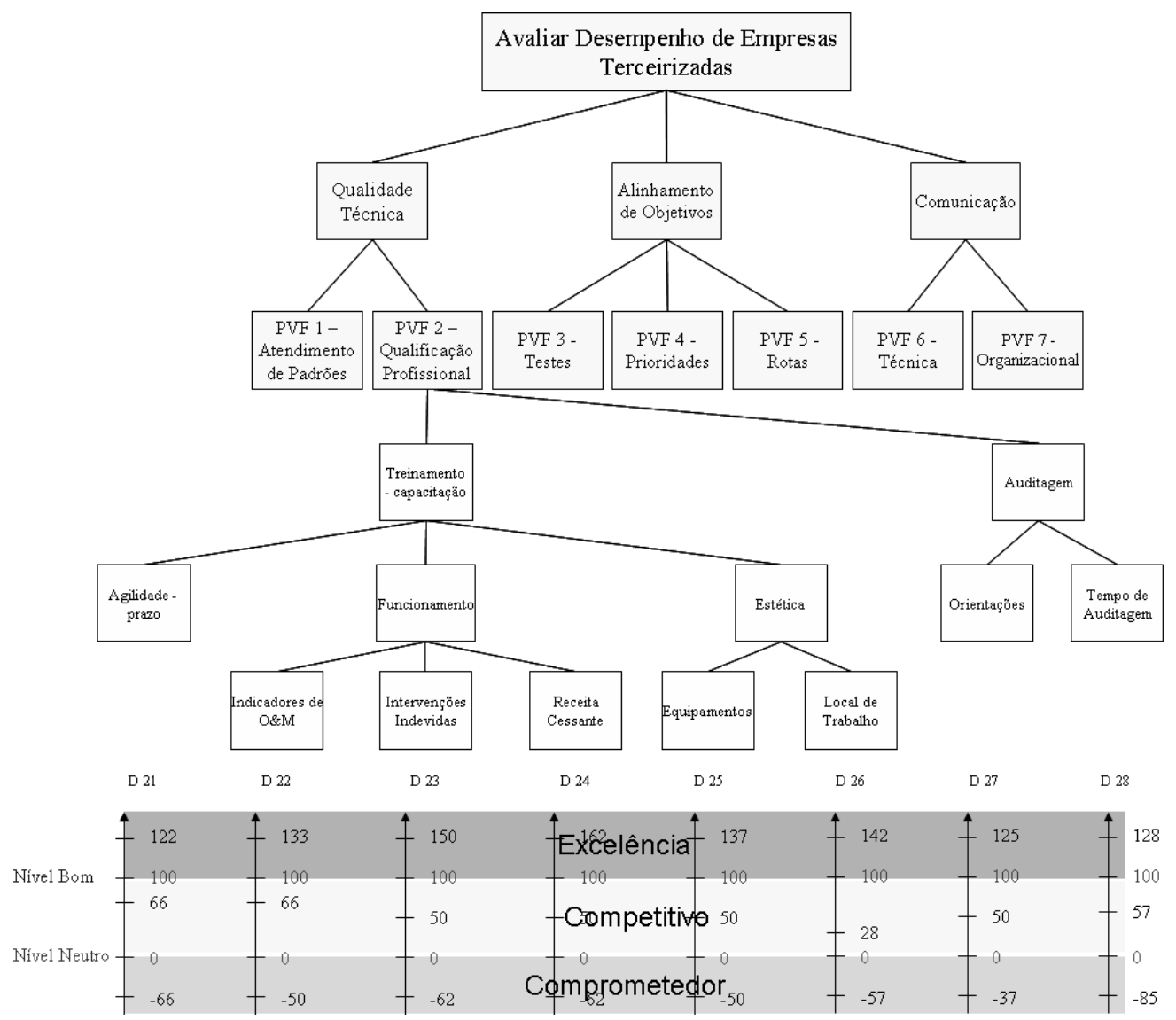

Figura 7 - Escalas cardinais do PVF Qualificação Profissional. 
Ao concluir a construção das funções de valor, a metodologia MCDA-C terá disponibilizado ao decisor um entendimento que lhe possibilita viabilizar a mensuração cardinal de cada aspecto operacional considerado relevante. Contudo, não lhe permitirá ainda visualizar a mensuração dos aspectos julgados estratégicos, os Pontos de Vista Fundamentais, e nem os táticos, os Pontos de Vista Elementares intermediários. Para dar prosseguimento ao processo de construção do entendimento, devem ser incorporadas informações que permitam integrar as escalas cardinais. Este é o propósito da etapa seguinte da metodologia MCDA-C.

\subsubsection{Taxas de Substituição}

A etapa seguinte na construção do entendimento consiste em agregar as avaliações locais de cada critério em uma avaliação global que possibilite a comparação de diferentes empresas terceirizadas. O entendimento se materializa na explicitação do modelo geral de avaliação que irá permitir mensurar a performance de cada terceirizada. A integração é realizada por meio das Taxas de Substituição, ou de Compensação. O método utilizado foi o de Comparação Par-a-Par do MACBETH, por não necessitar que o decisor expresse seus julgamentos de valor por meios numéricos, mas sim semânticos.

O processo tem início com a identificação da estrutura hierárquica que se deseja integrar por meio da definição das taxas que representam o juízo de valor preferencial do decisor, seja a estrutura hierárquica a representada em destaque na Figura 8. Isto é, deseja-se determinar as taxas para os PVEs Indicadores de O\&M, Intervenções Indevidas e Receita Cessante.

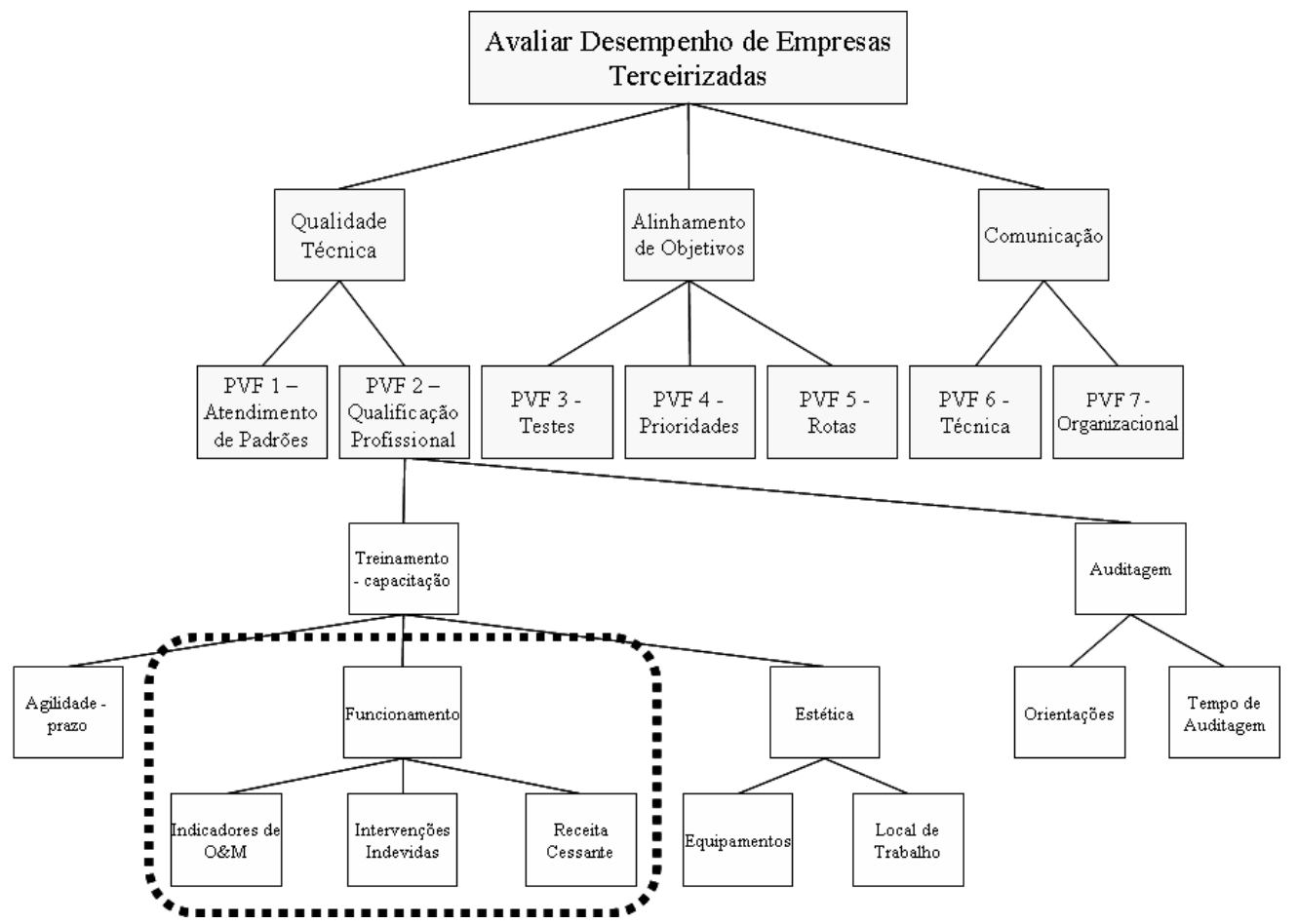

Figura 8 - Estrutura Hierárquica de Valor com destaque para os PVEs Indicadores de O\&M, Intervenções Indevidas e Receita Cessante. 
Inicialmente, é necessário criar ações potenciais que representem a contribuição da passagem do nível Neutro para o nível Bom, em cada um dos critérios que se deseja determinar as taxas, assim como uma ação de referência com desempenho Neutro em todos os pontos de vista, conforme apresentado na Figura 9.

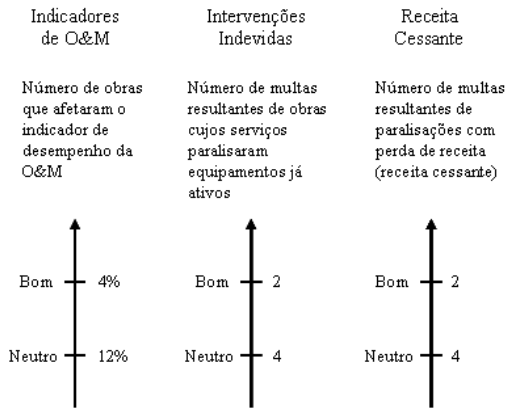

A1

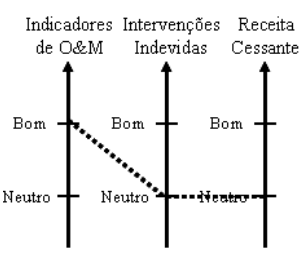

A3

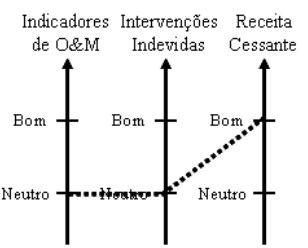

A0

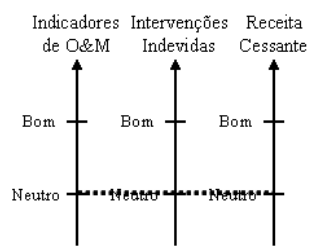

Figura 9 - Alternativas potenciais para determinar as taxas de substituição com a indicação dos respectivos níveis Bom e Neutro.

A seguir, ordenam-se as alternativas, o que pode ser realizado utilizando-se a Matriz de Roberts, conforme apresentado no Quadro 4. Para isso, o decisor deverá fornecer as informações sobre as alternativas potenciais construídas segundo seu juízo preferencial. Sempre que preferir a alternativa da linha, marca-se na coluna com a qual está comparando o valor 1, em caso contrário, zero. Ao final somam-se os valores das linhas e se obtém o grau de preferência conforme o valor da soma. Gera-se, desta forma, a hierarquização das alternativas, cuja ordem reflete a preferência do decisor para passar do nível Neutro para o nível Bom em cada PVE.

Quadro 4 - Matriz de Roberts da comparação dos PVEs Indicadores de O\&M, Intervenções Indevidas e Receita Cessante.

\begin{tabular}{|c|c|c|c|c|c|c|}
\hline & A1 & A2 & A3 & A0 & Soma & Ordem \\
\hline A1 & & 1 & 0 & 1 & 2 & 2 \\
\hline A2 & 0 & & 0 & 1 & 1 & 3 \\
\hline A3 & 1 & 1 & & 1 & 3 & 1 \\
\hline A0 & 0 & 0 & 0 & & 0 & 4 \\
\hline
\end{tabular}


As alternativas ordenadas são agora inseridas no software M-Macbeth, que se valendo da mesma lógica anterior fornece as Taxas de Substituição, como pode ser observado na Figura 10.

\begin{tabular}{|c|c|c|c|c|c|}
\hline & A3 & A1 & A2 & AD & Escala \\
\hline A3 & & muito forte & muito forte & extrema & 50,00 \\
\hline A1 & & & muito forte & muito forte & 33.00 \\
\hline A2 & & & & forte & 17.00 \\
\hline AD & & & & & 0.00 \\
\hline
\end{tabular}

Figura 10 - Taxas de substituição calculadas pelo M-Macbeth para os PVEs Indicadores de O\&M, Intervenções Indevidas e Receita Cessante.

Processo similar é realizado com todas as estruturas hierárquicas. A Figura 11 ilustra a Estrutura Hierárquica de Valor com as Taxas de Substituição do modelo construído, para os Pontos de Vista Fundamentais segundo os níveis de referência estabelecidos pelo Gestor de Projetos.
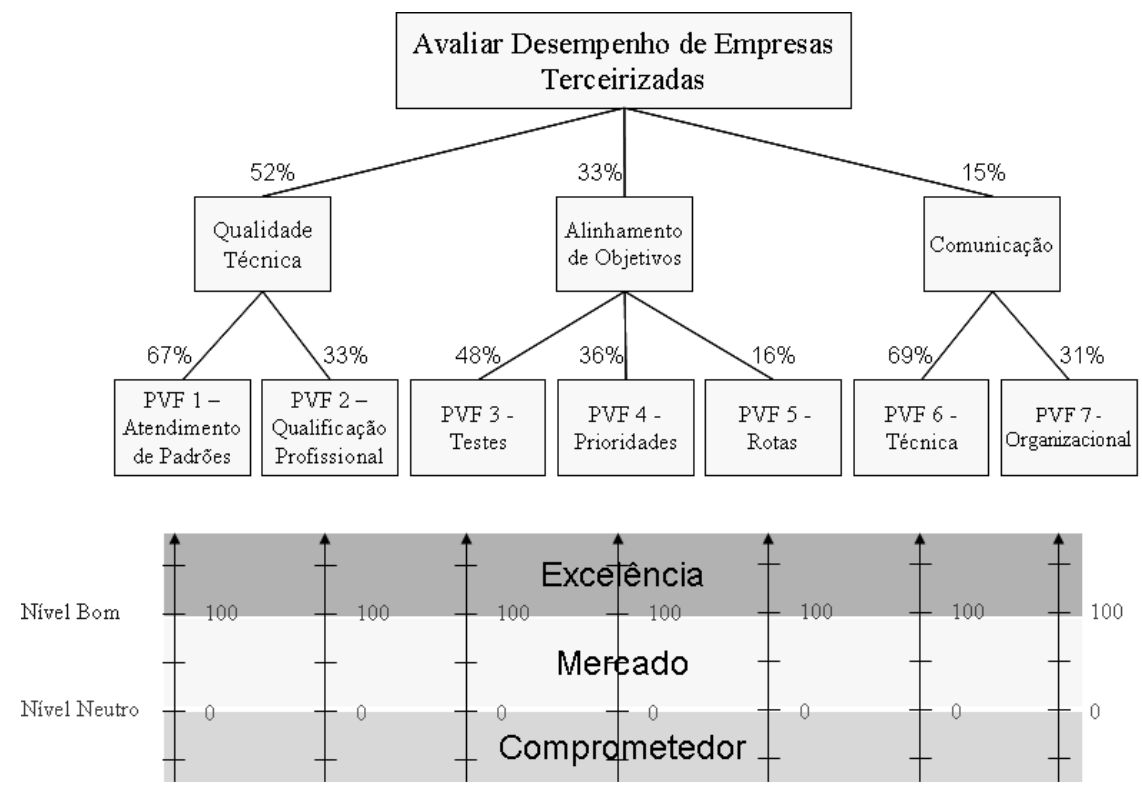

Figura 11 - Estrutura Hierárquica de Valor com as Taxas de Substituição.

\subsubsection{Avaliação Global e Perfil de Impacto da Situação Atual}

O modelo global será formado pela soma dos modelos de cada PVF. Neste caso, a equação do modelo global para os PVFs é:

$$
\begin{aligned}
V(a)= & 0,3484 \bullet V_{P V F 1}(a)+0,1716 \bullet V_{P V F 2}(a)+0,1584 \bullet V_{P V F 3}(a)+0,1188 \bullet V_{P V F 4}(a)+ \\
& +0,0528 \bullet V_{P V F 5}(a)+0,1035 \bullet V_{P V F 6}(a)+0,0465 \bullet V_{P V F 7}(a)
\end{aligned}
$$


Na equação (1), as constantes são o resultado do produto das taxas na cadeia ascendente, isto é, o primeiro valor 0,3484 corresponde a $0,67 * 0,52$, e assim sucessivamente.

Assim, para cada PVF, ter-se-á um modelo na forma genérica da Equação (2).

$V_{P V F_{k}}(a)=\sum_{i=1}^{n_{k}} w_{i, k} \bullet v_{i, k}(a)$

Em que:

$V_{P V F_{k}}(a)$ : valor global da ação $a$ do $\mathrm{PVF}_{\mathrm{k}}$, para $\mathrm{k}=1, \ldots \mathrm{m}$;

$v_{i, k}(a)$ : valor parcial da ação $a$ no critério $\mathrm{i}, \mathrm{i}=1, \ldots \mathrm{n}$, do $\mathrm{PVF}_{\mathrm{k}}$, para $\mathrm{k}=1, \ldots \mathrm{m}$;

$a$ : nível de impacto da ação $a$;

$w_{i, k}$ : taxas de substituição do critério $\mathrm{i}, \mathrm{i}=1, \ldots \mathrm{n}$, do $\mathrm{PVF}_{\mathrm{k}}$, para $\mathrm{k}=1, \ldots \mathrm{m}$;

$\mathrm{n}_{\mathrm{k}}$ : número de critérios do $\mathrm{PVF}_{\mathrm{k}}$, para $\mathrm{k}=1, \ldots \mathrm{m}$;

$\mathrm{m}$ : número de PVFs do modelo.

Para o $\mathrm{PVF}_{2}$ utilizado nas ilustrações, ter-se-ia:

$$
\begin{aligned}
& V_{P V F 2}(a)=0,67\left\{0,35 \bullet V_{\text {Agilidade }}+0,52\left[0,33 \bullet V_{\text {Indicações }}+0,17 \bullet V_{\text {Intervencões }}+0,50 \bullet V_{R \text { eceita }}\right]\right. \\
& \left.\quad+0,13\left[0,7 \bullet V_{\text {Equipamentos }}+0,3 \bullet V_{\text {Local }}\right]\right\}+0,33\left\{0,72 \bullet V_{\text {Orientações }}+0,28 \bullet V_{\text {Tempo.Auditagem }}\right\}
\end{aligned}
$$

A Figura 12 exibe a Estrutura Hierárquica de Valor para o $\mathrm{PVF}_{2}-$ Qualificação Profissional com as Taxas de Substituição dos PVEs que o compõem.

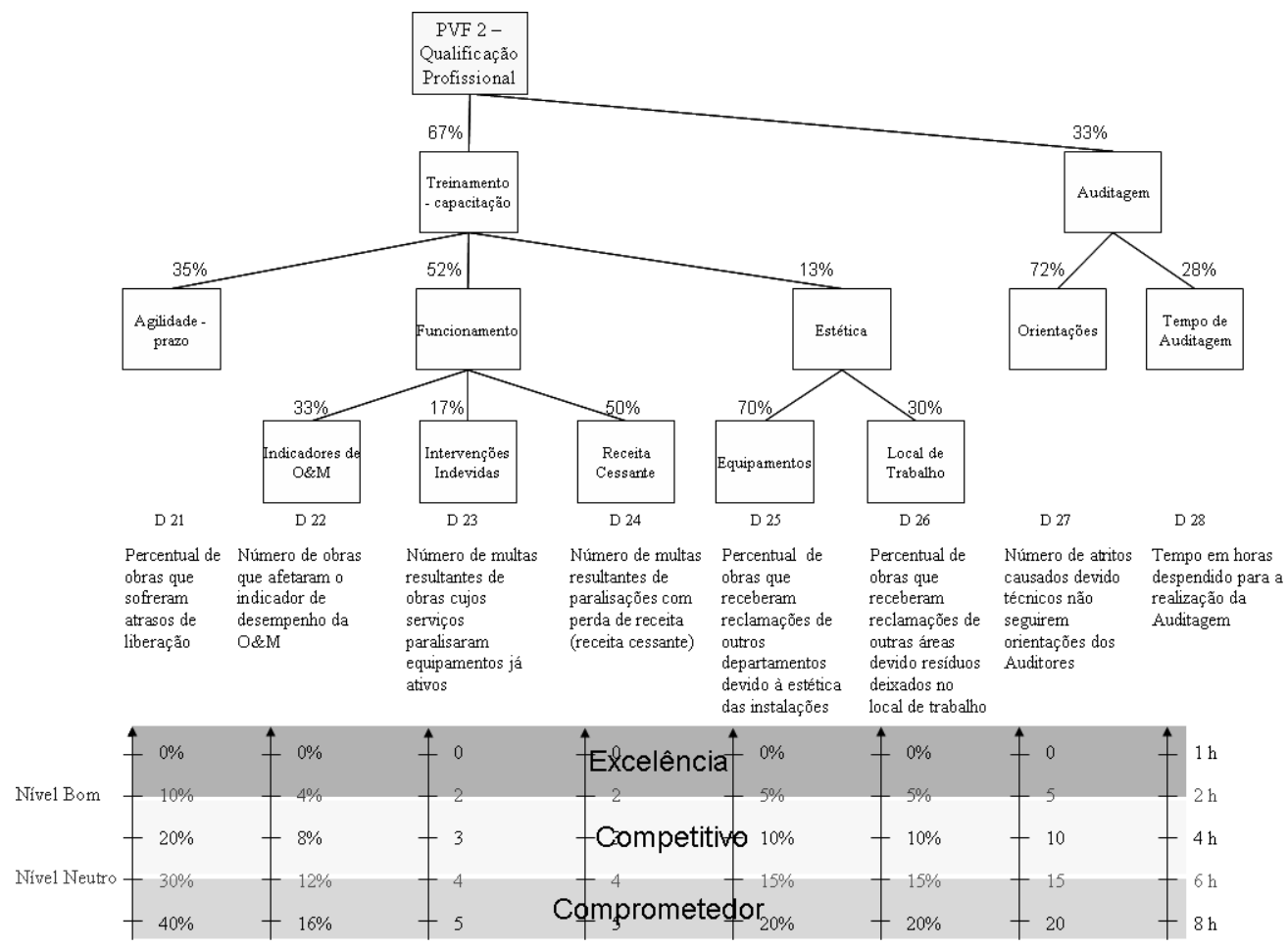

Figura 12 - Taxas de Substituição do $\mathrm{PVF}_{2}$. 
Repetindo o processo para os demais PVFs, tem-se o modelo global explicitado.

Pode-se, a partir desse momento, utilizar o modelo para apoiar o processo de gestão, o que é realizado com o suporte do modelo global de avaliação. O modelo ajuda a entender o grau de alinhamento das terceirizadas com os objetivos estratégicos do Gestor de Projetos, sejam elas já homologadas ou candidatas à homologação. Para ilustrar o estudo de caso, o decisor selecionou três empresas reais. Duas já homologadas que lhe prestam serviços para os projetos de comunicações de dados e uma candidata a prestar serviços para a empresa. Com o suporte do modelo global, o Gestor identificou a pontuação e o perfil de cada uma das três, conforme pode ser observado na Figura 13.

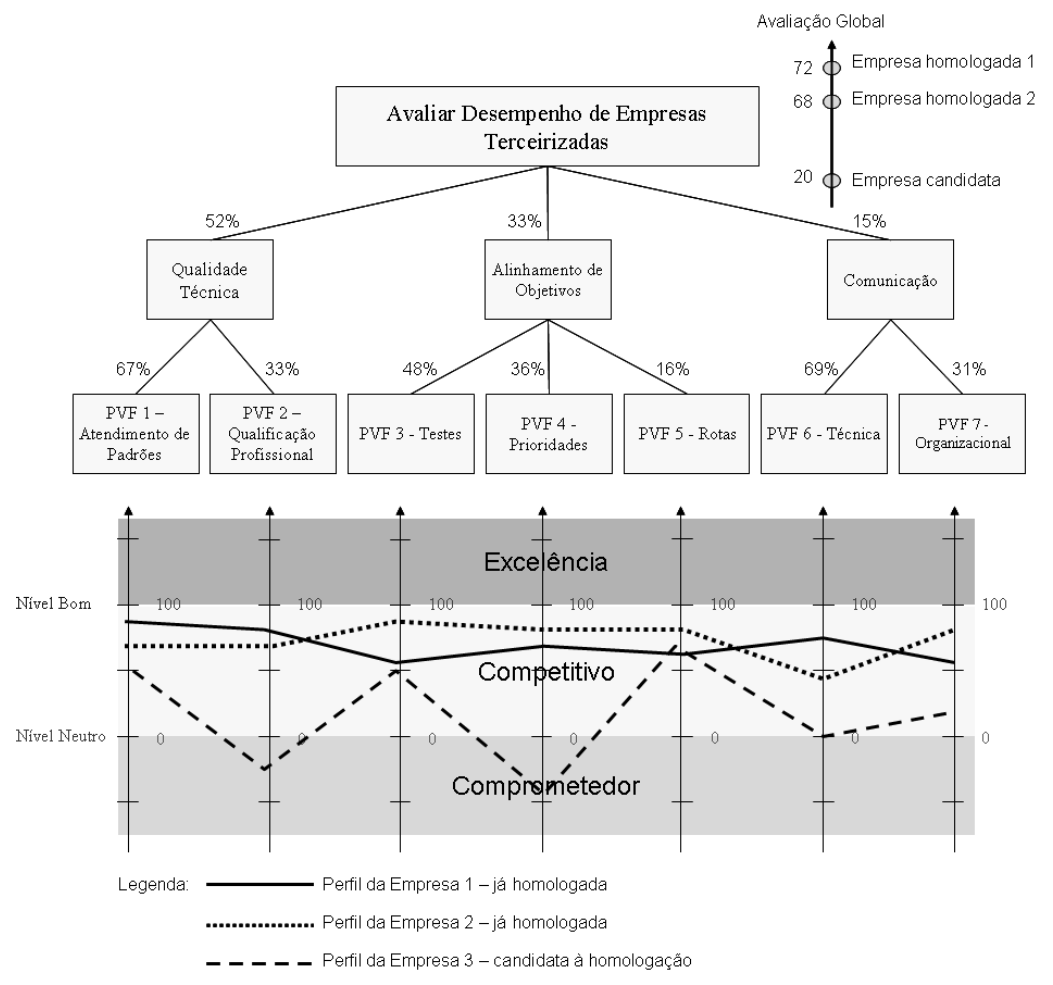

Figura 13 - Perfil de Impacto do status quo de duas empresas já homologadas e uma candidata à homologação.

Como pode ser verificado, o perfil das duas empresas já homologadas está alinhado com os critérios estratégicos de gerenciamento do Gestor. Já a candidata, mesmo apresentando desempenho competitivo nos critérios $\mathrm{PVF}_{1}$ - Atendimento de Padrões, $\mathrm{PVF}_{3}$ - testes, $\mathrm{PVF}_{5}$ - Rotas e $\mathrm{PVF}_{7}$ - Organizacional, está com dois PVFs com desempenho comprometedor: $\mathrm{PVF}_{2}$ - Qualificação Profissional e $\mathrm{PVF}_{4}$ - Prioridades. O modelo, ao ser construído segundo os valores e preferências do Gestor, permitiu visualizar o impacto das terceirizadas naquilo que o Gestor (decisor) considera relevante. Este entendimento o ajuda a identificar os locais específicos onde atuar. Agora, com o entendimento de onde é conveniente atuar, o Gestor necessita identificar ações e avaliar o impacto das mesmas para o alcance dos objetivos estratégicos. Na metodologia MCDA-C esta etapa é denominada Recomendações. 


\subsection{Recomendações}

A etapa de Recomendações na metodologia MCDA-C tem por função servir de apoio ao decisor para ajudá-lo a identificar formas para melhorar o desempenho do objeto que está sendo avaliado, assim como entender as consequências destas ações nos objetivos estratégicos do decisor, caso venham a ser implementadas. Como pode ser observado, esta etapa não possui um caráter prescritivo para informar o que fazer, mas sim um caráter de apoio para ajudar a construir ações e compreender suas consequências.

Seguindo esta filosofia de trabalho, e restringindo o processo de recomendações para a empresa que está em seu período de avaliação para homologação, o Gestor pode vinculá-la ao aperfeiçoamento de alguns critérios com performance atual em níveis comprometedores.

Esta etapa inicia identificando os PVFs onde se deseja aperfeiçoar a performance. Para o presente caso, os PVFs foram: $\mathrm{PVF}_{2}$ - Qualificação Profissional e $\mathrm{PVF}_{4}$ - Prioridades. Ilustra-se o processo para o $\mathrm{PVF}_{2}-$ Qualificação Profissional. Para entender as origens do desempenho da candidata neste PVF, visualiza-se o perfil de impacto da empresa candidata nos PVEs onde se situam as evidências da performance. Como pode ser visto na Figura 14, os PVEs Indicadores de O\&M, Receita Cessante e Local de Trabalho são aqueles onde o desempenho se situa em níveis mais comprometedores, logo, os principais candidatos a serem aperfeiçoados.

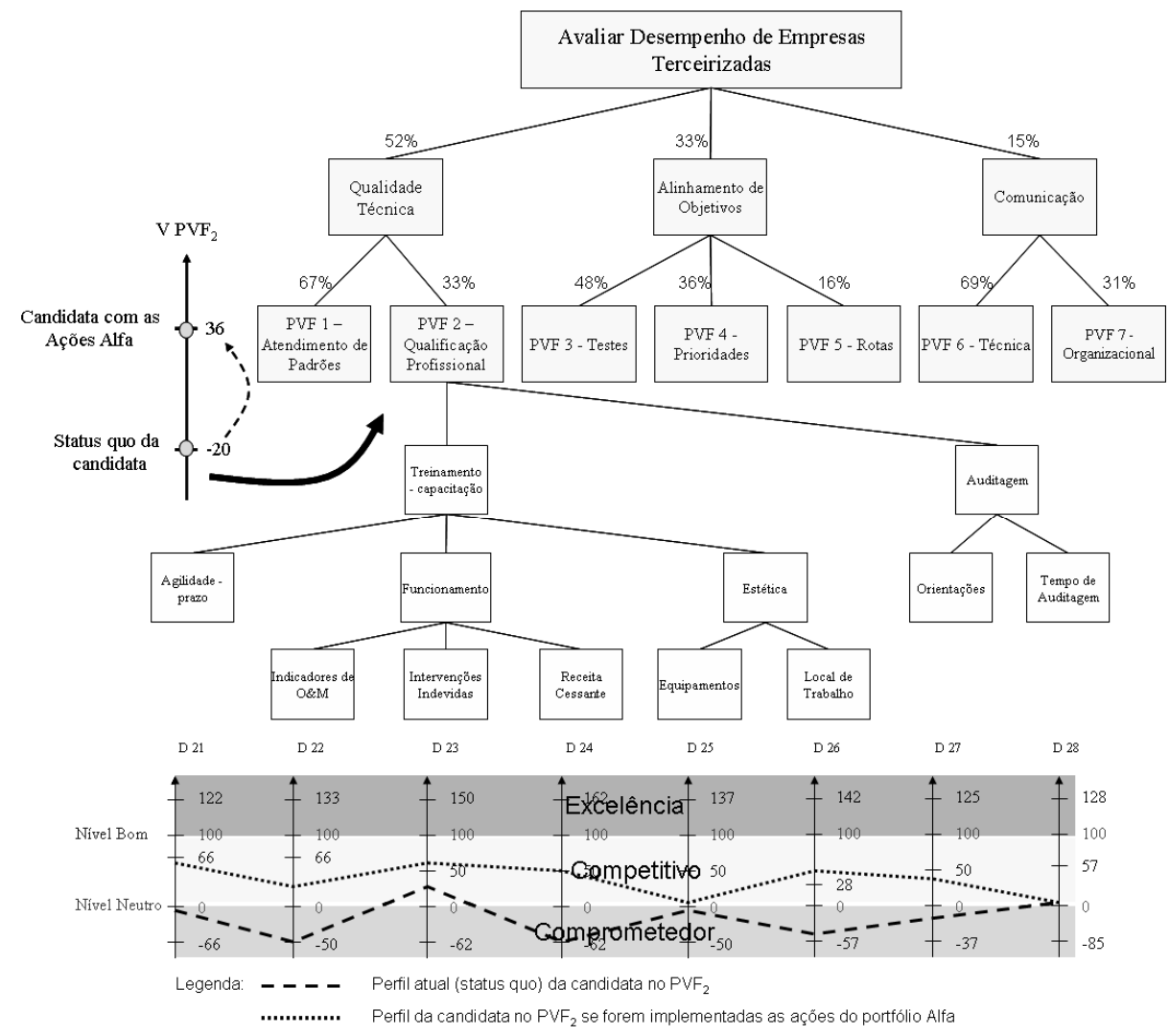

Figura 14 - Perfil de Impacto do $\mathrm{PVF}_{2}$ no status quo e com a aplicação das Ações Alfa à candidata à homologação. 
O processo consiste em visualizar o descritor e o correspondente status quo do nível de impacto da empresa sendo avaliada. A partir dessa informação, buscam-se com os atores envolvidos alternativas para fazer com que o impacto no PVE apresente uma melhora. Para ilustrar o processo, tome-se como exemplo o descritor do PVE - Receita Cessante, conforme Figura 15.

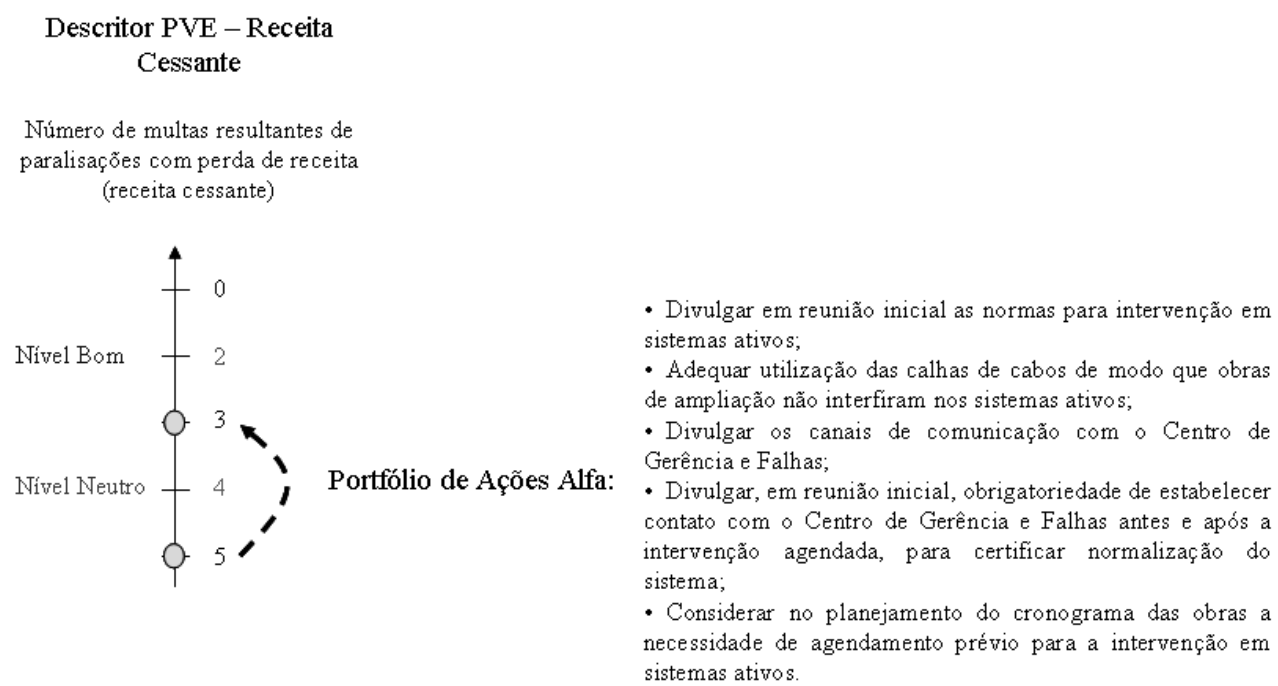

- Divulgar em reunião inicial as normas para intervenção em sistemas ativos:

- Adequar utilização das calhas de cabos de modo que obras de ampliação não interfiram nos sistemas ativos;

- Divulgar os canais de comunicação com o Centro de Gerência e Falhas;

- Divulgar, em reunião inicial, obrigatoriedade de estabelecer contato com o Centro de Gerência e Falhas antes e após a intervenção agendada, para certificar normalização do sistema;

- Considerar no planejamento do cronograma das obras a necessidade de agendamento prévio para a intervenção em sistemas ativos.

Figura 15 - Alteração na performance no Descritor do PVE - Receita Cessante com aplicação das Ações Alfa.

Como pode ser notado, foram identificadas cinco ações que, segundo a percepção dos atores que as identificaram, permitirão elevar a performance do PVE - Receita Cessante de 5 ocorrências para 3 ocorrências (ou de -60 para 50 na escala cardinal da Figura 14). Igual procedimento foi realizado com os demais PVEs, fazendo com que a performance se elevasse aos valores apresentados no Perfil de Impacto da Figura 14. Este conjunto de ações, caso implementadas, elevaria a performance do $\mathrm{PVF}_{2}-$ Qualificação Profissional de -20 para +36 .

Percebe-se, assim, que a etapa de Recomendações na metodologia MCDA-C fornece os meios para o decisor identificar:

- Onde é conveniente atuar;

- Processo para gerar ações para promover o aperfeiçoamento;

- A visualização das consequências da implementação em nível local ou operacional (no PVE), em nível tático (no PVF) e estratégico (Global).

Outros cenários podem igualmente ser desenvolvidos e testados. Esta é a função da etapa de Recomendações, ajudar a construir entendimento para que o decisor possa identificar os meios (ações) cujas consequências melhor atendam seus objetivos. Algumas vezes este entendimento poderá requerer que sejam simulados cenários onde os parâmetros do modelo desenvolvido sejam testados quanto às consequências de uma eventual variação. Neste caso, a etapa de Recomendações faz uma análise de sensibilidade, o que pode ser realizada com o 
apoio de outros softwares como o VISA (Visual Thinking, 1995) e o HIVIEW for Windows (Crysalis, 1997). Sempre visando trazer condições para melhor entender as consequências do contexto nos valores do decisor.

Com isto, a metodologia MCDA-C em suas três fases: Estruturação, Avaliação e Recomendações; mantém seus pressupostos construtivistas.

\section{Considerações Finais}

O presente artigo objetivou construir o entendimento do decisor, materializado em um modelo para avaliar o desempenho de empresas terceirizadas para uma organização da área de telecomunicações. Por se tratar de um contexto complexo, com interesses conflitantes e onde os atores envolvidos não estavam seguros a respeito do que deveria ser tido em conta, foi utilizada a metodologia MCDA-C como instrumento de intervenção. O trabalho contemplou as etapas de Estruturação, Avaliação e Recomendações. As informações utilizadas para construir o modelo foram obtidas prioritariamente por meio de entrevistas com o Gestor de Projetos da organização e, quando necessário, foram realizadas pesquisas documentais para detalhar aspectos específicos. O trabalho teve caráter exploratório na forma de estudo de caso, valendo-se de uma abordagem quali-quantitativa, e uma lógica de pesquisa mista, indutiva nas etapas de estruturação e recomendações e dedutiva na etapa de avaliação.

O processo de apoio propiciado pelos facilitadores em forma participativa, sistêmica e sistemática permitiu ao decisor refletir sobre o contexto e assim identificar, organizar, mensurar e integrar os aspectos por ele julgado como necessários e suficientes para avaliar as terceirizadas. Com isto, respondendo a pergunta da pesquisa - quais os critérios a serem considerados no processo de homologação de empresas terceirizadas, em um modelo que se propõe a apoiar o gerenciamento desses recursos de tal forma a promover a competitividade organizacional.

O objetivo geral da pesquisa consistiu em construir um modelo para avaliar o desempenho de empresas terceirizadas, de tal maneira a permitir o aprimoramento do processo de seleção e gestão dos serviços terceirizados em uma empresa de telecomunicações. Este objetivo foi alcançado por meio da equação 1 , a qual foi operacionalizada pelos objetivos específicos propostos. $\mathrm{O}$ alcance do objetivo geral foi construído gradativamente com os objetivos específicos.

A metodologia MCDA-C trabalha com processos personalizados aos atores, contexto e momento, desta forma, o trabalho teve início com a contextualização e explicitação dos atores envolvidos, notadamente o decisor e os facilitadores, conforme apresentado na seção 3.1.1. Contextualização, Subsistema de Atores e Rótulo, atendendo assim ao objetivo específico 1.

O decisor, na seção 3.1.3. Mapas Meios-Fins e Árvore de Pontos de Vista Fundamentais, explicitou que os critérios a serem tidos em conta são: 1- Atendimento de Padrões; 2- Qualificação Profissional; 3- Testes; 4- Prioridades; 5- Rotas; 6- Técnica; e 7- Organizacional. Assim, atende-se ao objetivo específico 2 - Identificar os critérios que o decisor considera necessários e suficientes para avaliar as empresas terceirizadas.

Para atender ao objetivo do trabalho de construir um modelo para avaliar o desempenho de empresas terceirizadas, de tal maneira a permitir o aprimoramento do processo de seleção e gestão dos serviços terceirizados em uma empresa de telecomunicações, foi necessário mensurar o alcance de cada um dos critérios e integrá-los. A mensuração ordinal foi 
realizada na fase de estruturação e exibida na seção 3.1.4. Estrutura Hierárquica de Valor e Descritores. A Figura 5 apresenta a mensuração ordinal do critério $\mathrm{PVF}_{2}-$ Qualificação Profissional. As escalas construídas pelo decisor, nesta fase, foram alfa-numéricas, uma vez que não atendiam aos quesitos da unidade e da origem (zero representar ausência de medida) e, portanto, foram transformadas em escalas cardinais para admitirem operações numéricas. Esta transformação foi realizada na fase de avaliação mostrada na seção 3.2. Avaliação, e ilustrada para o descritor (escala ordinal) Cláusulas Contratuais, na Figura 6. As Funções de Valor (escalas cardinais) para o $\mathrm{PVF}_{2}$ - Qualificação Profissional encontram-se na Figura 7, atendendo assim ao objetivo específico 3 - Construir escalas ordinais e cardinais para mensurar esses critérios, segundo a percepção do decisor.

A integração foi realizada ainda na fase de Avaliação e apresentada na seção 3.2.2. Taxas de Substituição. O processo de integração foi ilustrado para o PVE - Funcionamento, conforme apresentado na Figura 10. A integração global foi explicitada na seção 3.2.3. Avaliação Global e Perfil de Impacto da Situação Atual, por meio da equação 1 (Equação Global), atendendo integralmente o objetivo específico 4 - Integrar os critérios via taxas de compensação.

O objetivo específico 5 - Ilustrar o entendimento gerado pela evidenciação do perfil de impacto de uma terceirizada, e o 6 - Evidenciar o processo de avaliação das terceirizadas, foram realizados na mesma seção 3.2.3 para três empresas, Figura 13.

O objetivo específico 7 - Evidenciar o processo de geração de ações de aperfeiçoamento, foi realizado na seção 3.3. Recomendações, em que para uma candidata à homologação foi analisado seu perfil e evidenciadas onde estão as oportunidades para melhorar sua performance. A partir de então, a metodologia MCDA-C mostrou como gerar ações de aperfeiçoamento e na Figura 14 suas consequências ao mostrar que a pontuação da mesma no $\mathrm{PVF}_{2}$ - Qualificação Profissional mudaria de -20 para +36 se o portfólio de ações de aperfeiçoamento recomendadas fosse implementado. Com isto, a metodologia MCDA-C atendeu à pergunta da pesquisa e aos objetivos geral e específicos.

O modelo construído no Estudo de Caso foi legitimado pelo decisor em cada etapa de sua construção, e com sua utilização, o decisor e a operadora de telecomunicações passaram a contar com um instrumento que oportuniza a melhoria contínua na gestão do desempenho das empresas terceirizadas, aberto a ações criativas e inovadoras para a melhora do desempenho.

Dentre as contribuições do trabalho, destacam-se: no nível teórico, a evidenciação das diferenças entre a MCDA-C e a MCDA; no nível prático, a demonstração da potencialidade da metodologia MCDA-C para, em contextos onde o decisor não consegue explicitar o que leva em conta para decidir, construir, a partir da sua participação comprometida, os critérios que ele julga necessários e suficientes para avaliar o contexto.

Como limitação da pesquisa, ressalta-se o caráter de personalização da mesma, não recomendando a aplicação do modelo representado pela equação 1 em outros contextos, uma vez que o modelo foi construído segundo os valores e preferências de um decisor específico. Quanto ao processo proposto pela metodologia MCDA-C, as limitações principais são: requer a participação comprometida do decisor e o elevado tempo que o processo demanda.

Como recomendações para trabalhos posteriores, que na presente pesquisa foi restrito à percepção do gestor de projetos da empresa de telecomunicações, que o contexto do problema seja analisado segundo a percepção dos terceirizados e, de posse dos dois modelos, se tenha um instrumento de negociação para identificar ações sinergéticas. 
Como recomendações para os pesquisadores da área multicritério, que deixem clara sua lógica de pesquisa. Isto é, informem se os critérios utilizados são os construídos a partir das percepções do(s) decisor(es), e neste caso apresentem as evidências de como foram feitos, ou se são utilizados os critérios externos para os quais já se tem dados disponíveis ou determinados indiretamente (casos similares, revisão bibliográfica, data mining, etc.) e são os que o decisor deveria ter em conta (visão racionalista). O primeiro grupo trabalha com a metodologia MCDA-C, o segundo, a MCDA tradicional.

\section{Agradecimentos}

Agradecemos aos três anônimos referees, pelas enriquecedoras considerações.

\section{Referências Bibliográficas}

(1) Azevedo, J. (2001). Aplicação da metodologia multicritério de apoio à decisão na seleção de centros de usinagem para uma central de usinagem. Universidade Federal de Santa Catarina, Dissertação de Mestrado em Engenharia de Produção.

(2) Bana e Costa, C.A. (1990). Readings in Multicriteria Decision Aid. Springer-Verlag, Berlin.

(3) Bana e Costa, C. A. (1993). Três convicções fundamentais na prática do apoio à decisão. Pesquisa Operacional, 13, 1-12.

(4) Bana e Costa, C.A. \& Beinat, E. (2005). Model-structuring in Public Decision-aiding. Working paper LSE OR 05-79, London School of Economics, London.

(5) Bana e Costa, C.A.; De Corte, J.M. \& Vansnick, J.C. (2005). On the mathematical foundations of macbeth. In: Multicriteria Decision Analysis: state of the art survey [edited by J.F. Greco and S.M. Ehrgott], Springer Verlag, Boston, Dordrecht, London, 409-442.

(6) Bana e Costa, C.A.; Ensslin, L.; Corrêa, É.C. \& Vansnick, J.C. (1999). Decision support systems in action: integrated application in a multicriteria decision aid process. European Journal of Operational Research, 113, 315-335.

(7) Bana e Costa, C.A.; Lourenço, J.C.; Chagas, M.P. \& Bana e Costa, J.C. (2008). Development of reusable bid evaluation models for the portuguese electric transmission company. Decision Analysis, 5, 22-42.

(8) Bana e Costa, C.A.; Steward, T. \& Vansnick, J.C. (1995). Multicriteria Decision Analysis: some thought based on the tutorial and discussion sessions of the esigma meetings. Proceedings of the EURO XIV Conference, Jerusalem, 3-6 July 1995.

(9) Bana e Costa, C.A. \& Vansnick, J.C. (1995). Uma nova abordagem ao problema da construção de uma função de valor cardinal: MACBETH. Investigação Operacional, 15, 15-35.

(10) Barzilai, J. (2001). On the Foundations of Measurement. Proceedings of the 2001 IEEE International Conference on Systems, Man and Cybernetics, Tucson, 7-10 October 2001.

(11) Bergamaschi, S. (2004). Modelos de gestão da terceirização de tecnologia da Informação: um estudo exploratório. Universidade de São Paulo, Tese de Doutorado em Administração.

(12) Campos, V.R. \& Almeida, A.T. de. (2006). Modelo multicritério de decisão para localização de Nova Jaguaribara com VIP Analysis. Pesquisa Operacional, 26, 91-107. 
(13) Chen, Y.; Kilgour, D.M. \& Hipel, K.W. (2008). A case-based distance method for screening in multiple-criteria decision aid. Omega, 36, 373-383.

(14) Correa, E.C. (1996). Construção de um modelo multicritério de apoio ao processo decisório. Universidade Federal de Santa Catarina, Dissertação de Mestrado em Engenharia de Produção.

(15) Crysalis Ltd. (1997). EQUITY for Windows User Manual.

(16) Dvir, D.; Lipovetsky, S.; Shenhar, A. \& Tishler, A. (1998). In search of project classification: a non-universal approach to project success factors. Research Policy, 27, 915-935.

(17) Eden, C. \& Ackermann, F. (1992). The analysis of cause maps. Journal of Management Studies, 29, 309-324.

(18) Ensslin, L.; Dutra, A. \& Ensslin, S.R. (2000). MCDA: a construtivist approach to the management of human resources at a governmental agency. International Transactions in Operational Research, 7, 79-100.

(19) Ensslin, L.; Longaray, A.A. \& Mackness, J.R. (2005). Decision Support System to Aid a Patient with Stress to Identify Opportunities to Improve her Quality of Life. Proceedings of the Annual International Scientific Conference Operations Research, Bremen, 2005, 7-9 September, 2005.

(20) Ensslin, L.; Montibeller, G.N. \& Noronha, S.M. (2001). Apoio à Decisão: Metodologias para Estruturação de Problemas e Avaliação Multicritério de Alternativas. Insular, Florianópolis.

(21) Gomes, C.F.S. (2005). Using MCDA methods THOR in an application for outranking the ballast water management options. Pesquisa Operacional, 25, 11-28.

(22) Goodwin, P. \& Wright, G. (1998). Decision Analysis for Management Judgment. John Wiley \& Sons, Chichester.

(23) Hays, R.H. \& Pisano, P.G. (1994). Beyond world-class: the new manufacturing strategies. Harvard Business Review, 72, 77-86.

(24) Heijden, K.V.D. (1996). Scenarios: The Art of Strategic Conversation. John Wiley \& Sons, Chichester.

(25) IBGE. (2007). Instituto Brasileiro de Geografia e Estatística. $<$ http://www.ibge.gov.br/estadosat/perfil. php?sigla=sc $>$. Current: Mai 2007.

(26) Igarashi, D.C.C.; Ensslin, S.R.; Ensslin, L. \& Paladini, E.P. (2008). A qualidade do ensino sob o viés da avaliação de um programa de pós-graduação em contabilidade: proposta de estruturação de um modelo híbrido. Revista de Gestão USP, 43, 117-137.

(27) Keeney, R.L. (1992). Value-focused thinking: a path to creative decisionmaking. Harvard University Press, London.

(28) Keeney, R.L. \& Raiffa, H. (1976). Decisions with Multiple Objectives: Preferences and Value Trade-offs. Wiley, New York.

(29) Landry, M. (1995). A note on the concept of problem. Organization Studies, 16, 315-343.

(30) Landry, M.; Pascot, D. \& Briolat, D. (1985). Can DSS evolve without changing our view of the concept of 'problem'? Decision Support Systems, 1, 25-36. 
(31) Longaray, A.A.; Ensslin, L. \& Mackness, J. (2005). Use of Constructivist Multi-criteria Decision Aid Model with Soft Systems Methodology to Improve the Quality of Life of a Patient with Stress. Proceedings of the International Scientific Congress of Operations Research, Bremen, 2005, 234-235.

(32) Munda, G. (2003). Between science and democracy: the role of "social multi-criteria evaluation (SMCE). European Working Group "Multicriteria Aid for Decisions", 7(3), 1-5.

(33) Ramos, L.G.T. (2002). A gestão dos processos de terceirização e sua implementação na indústria automobilística. Universidade de Taubaté, Monografia de Especialização em Economia, Ciências Contábeis, Administração e Secretariado.

(34) Roy, B. (1993). Decision science or decision-aid science? European Journal of Operational Research, 66, 184-203.

(35) Roy, B. (1994). On operational research and decision aid. European Journal of Operational Research, 73, 23-26.

(36) Roy, B. (1996). Multicriteria Methodology for Decision Aiding. Kluwer Academic Publishers, Dordrecht.

(37) Roy, B. (2005). Paradigms and Challenges, Multiple Criteria Decision Analysis - State of the Art Survey. In: Multicriteria Decision Analysis: state of the art survey [edited by J.F. Greco and S.M. Ehrgott], Springer Verlag, Boston, Dordrecht, London, 03-24.

(38) Roy, B. \& Bouyssou, D. (1993). Decision-aid: an elementary introduction with emphasis on multiple criteria. Information Science and Technology, 2, 109-123.

(39) Roy, B. \& Vanderpooten, D. (1996). The european school of MCDA: emergence, basic features and current works. Journal of Multi-Criteria Decision Analysis, 5, 22-38.

(40) Sannemann, G.D.R.; Ensslin, L.; Ensslin, S.R. \& Dutra, A. (2006). Reflections on the Structuring of the Organizational Performance Problem using an MCDA-C Approach from an Integrative Systemic-synergetic Perspective. Proceedings of the 21st European Conference on Operational Research, Iceland, 2-5 July 2006.

(41) Shenhar, A.J. (2001). One size does not fit all projects: exploring classical contingency domains. Management Science, 47, 394-414.

(42) Skinner, W. (1986). The productivity paradox. Management Review, 75, 41-45.

(43) Steward, T. (2005). Dealing with uncertainties in MCDA. In: Multicriteria Decision Analysis: state of the art survey [edited by J.F. Greco and S.M. Ehrgott], Springer Verlag, Boston, Dordrecht, London, 445-470.

(44) Visual Thinking International Ltd. (1995). V.I.S.A. for Windows Manual.

(45) Zambon, K.L.; Carneiro, A.A. de F.M.; Silva, A.N.R. da \& Negri, J.C. (2005). Análise de decisão multicritério na localização de usinas termoelétricas utilizando SIG. Pesquisa Operacional, 25, 183-199.

(46) Zimmermann, H. (2000). An application-oriented view of modeling uncertainty. European Journal of Operations Research, 122, 190-198. 